\title{
IDENTIFICAÇÃO DOS INIMIGOS NATURAIS DE Lonomia obliqua Walker, 1855 (Lepidoptera, Saturniidae) E POSSÍVEIS FATORES DETERMINANTES DO AUMENTO DA SUA POPULAÇÃO
}

ROBERTO HENRIQUE PINTO MORAES

Dissertação apresentada à Escola Superior de Agricultura "Luiz de Queiroz" Universidade de São Paulo, para obtenção do título de Mestre em Ciências, Área de Concentração: Entomologia.

PIRACICABA

Estado de São Paulo - Brasil

Maio - 2002 


\section{IDENTIFICAÇÃO DOS INIMIGOS NATURAIS DE Lonomia obliqua Walker, 1855 (Lepidoptera, Saturniidae) E POSSÍVEIS FATORES DETERMINANTES DO AUMENTO DA SUA POPULAÇÃO}

ROBERTO HENRIQUE PINTO MORAES

Biólogo

Orientador: Prof. Dr. EVONEO BERTI FILHO

Dissertação apresentada à Escola Superior de Agricultura "Luiz de Queiroz" Universidade de São Paulo, para obtenção do título de Mestre em Ciências, Área de Concentração: Entomologia.

PIRACICABA

Estado de São Paulo - Brasil

Maio - 2002 


\title{
Dados Internacionais de Catalogação na Publicação (CIP) DIVISÃO DE BIBLIOTECA E DOCUMENTAÇÃO - ESALQ/USP
}

\author{
Moraes, Roberto Henrique Pinto \\ Identific ação dos inimigos na tura is de Lonomia obliqua Walker, 1855 \\ (Lepidoptera, Satumiidae) e possíveis fatores determina ntes do aumento \\ da sua população / Roberto Henrique Pinto Moraes. - - Piracicaba, 2002. \\ 58 p. : il. \\ Dissertação (mestrado) - - Escola Superior de Agricultura Luiz de \\ Queiroz, 2002. \\ Bibliografia.
}

1. Controle biológico 2. Insetos vetores 3. Lagartas 4. Ta turana I. Título

CDD 616.968

"Permitida a cópia total ou parcial deste documento, desde que citada a fonte - O autor" 
À Memória de Lauro Pereira Travassos Filho 


\section{AGRADECIMENTOS}

Ao Prof. Dr. Evoneo Berti Filho, pela orientação, paciência e amizade.

À Dra.Toshie Kawano, Diretora do Laboratório de Parasitologia do Instituto Butantan, pelo incentivo.

À Dra. Fan Hui Wen, Diretora do Hospital Vital Brazil, pelas valiosas opiniões e pelo companheirismo nas viagens.

À Dra.Darci Moraes Barros Battesti, pesquisadora do Laboratório de Parasitologia do Instituto Butantan, pelo constante incentivo e opiniões.

Às Biólogas do Laboratório de Parasitologia do Instituto Butantan, Ana Vieira da Costa, Vanessa Maria Martins Rebello e Valéria Castilho Onofrio, pela amizade, companheirismo e por tornarem o ambiente de trabalho sempre alegre.

Ao Dr. Ronaldo Toma do Museu de Zoologia da USP, pela identificação dos Díptera.

Ao Dr. José Luiz Wolff, da Universidade de Mogi das Cruzes, pela identificação do vírus.

Ao Dr. Luiz Carlos Camargo Barbosa da ESALQ, pela identificação do nematóide.

À Keiko Uramoto, pelo incentivo e companheirismo nas inúmeras viagens a Piracicaba.

Ao CNPq, pelo auxílio financeiro.

A todos aqueles que de alguma forma me auxiliaram na execução deste trabalho. 


\section{SUMÁRIO}

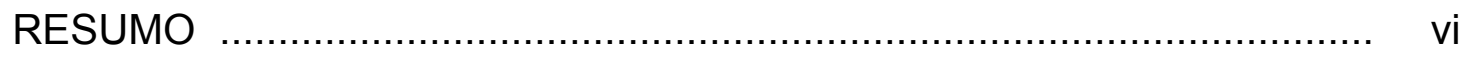

Página

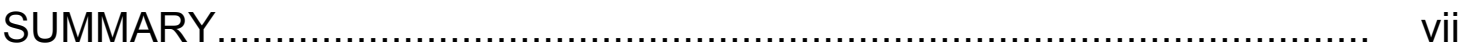

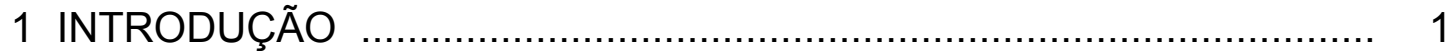

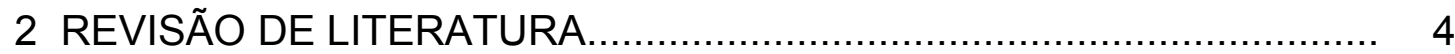

2.1 Biologia, morfologia, distribuição geográfica, plantas hospedeiras e sistemática ............................................................................... 4

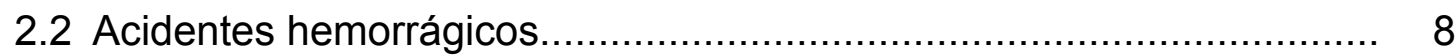

2.3 Bioquímica e fisiopatologia do envenenamento ............................... 9

2.4 Lonomias e o meio ambiente..................................................... 9

2.5 Inimigos naturais.................................................................... 10

3 MATERIAL E MÉTODOS ............................................................ 11

3.1 Obtenção das lagartas de Lonomia obliqua...................................... 11

3.2 Envio, recebimento e manutenção das lagartas em laboratório........... 12

3.3 Criação ............................................................................. 13

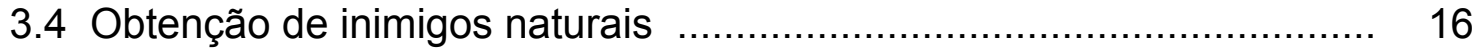

3.4.1 Himenópteros ............................................................ 17

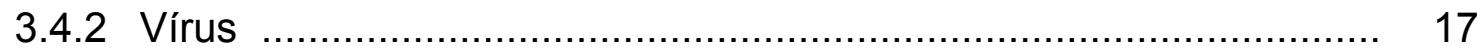

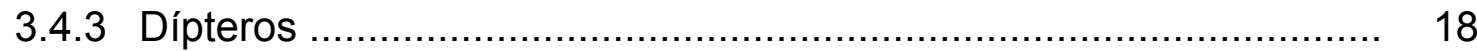

3.4.4 Nematóide …............................................................... 19

3.4.5 Hemíptero ....................................................................... 20

3.5 Região de estudo.............................................................. 21

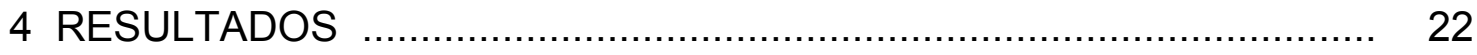

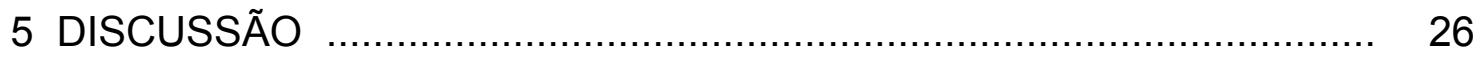

5.1 Dípteros e himenóptero como inimigos naturais de L. obliqua .............. 27 
5.2 Vírus (NPV) como agente entomopatogênico de L. obliqua ................. 28

5.3 Nematóide como parasita de L. obliqua ........................................... 29

5.4 Predação de $L$. obliqua por hemíptero heteróptero ............................. 30

5.5 Aspectos bióticos e abióticos das regiões de ocorrência de L.obliqua ... 31

6 CONCLUSÕES …..................................................................... 37

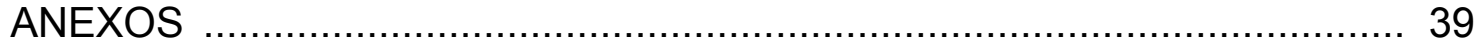

REFERÊNCIAS BIBLIOGRÁFICAS ................................................. 53 


\title{
IDENTIFICAÇÃO DOS INIMIGOS NATURAIS DE Lonomia obliqua Walker, 1855 (Lepidoptera, Saturniidae) E POSSÍVEIS FATORES DETERMINANTES DO AUMENTO DA SUA POPULAÇÃO
}

\author{
Autor: ROBERTO HENRIQUE PINTO MORAES \\ Orientador: Prof. Dr. EVONEO BERTI FILHO
}

\section{RESUMO}

Este trabalho teve como principal objetivo, identificar os inimigos naturais de Lonomia obliqua Walker, 1855, lagarta da síndrome hemorrágica em humanos. Através de exemplares de L. obliqua coletados no campo e criados em laboratório, foi possível a obtenção de insetos das ordens Diptera, Hymenoptera e Hemiptera além de Vírus e Nematóide, todos atuando como inimigos naturais. A partir do conhecimento das localidades onde ocorreram os acidentes hemorrágicos, localizou-se e reconheceu-se o hábitat atual desses insetos. Comparando-se as características bióticas e abióticas atuais dessas localidades, geralmente rurais, com aquelas existentes no final do século XIX, época em que ocorreu a formação desses municípios, procurou-se discutir os principais fatores que possivelmente tiveram influência no aumento da população dessa espécie. 


\title{
IDENTIFICATION OF THE NATURAL ENEMIES OF Lonomia obliqua Walker, 1855 (Lepidoptera, Saturniidae) AND POSSIBLE FACTORES INFLUENCING THE INCREASING OF ITS POPULATION
}

\author{
Author: ROBERTO HENRIQUE PINTO MORAES
}

Adviser: Prof. Dr. EVONEO BERTI FILHO

\section{SUMMARY}

The main purpose of this study was to identify the natural enemies of Lonomia obliqua Walker, 1855, the caterpillar responsible for the hemorrhagic syndrome in human beings. From immatures of $L$. obliqua, collected in the field and reared in the laboratory, insects of the orders Diptera, Hymenoptera and Hemiptera, and also viruses and nematodes, were obtained. Based on the knowledge of the localities where hemorrhagic accidents were registered, the insect habitats were recognized. Comparing biotic and abiotic characteristics of these localities, generally rural, ones with those of the end of the XIX century, when the municipalities were created, an attempt was made to discuss the main factors might have influencing the increase of the species population. 


\section{INTRODUÇÃO}

Dentro da Ordem Lepidoptera, algumas famílias possuem espécies com representantes na fase larval responsáveis por acidentes. No Brasil, destacam-se como agentes etiológicos de problemas dermatológicos, lagartas das famílias Megalopygidae, Saturniidae e Limacodidae (Moraes, 1997).

Em culturas de seringais do Estado do Pará, são relativamente comuns relatos de acidentes com lagartas de Premolis semirufa, um representante da família Arctiidae, popularmente conhecido por "Pararama", que causa problemas reumatológicos e deformantes nas mãos dos seringueiros (Costa,1991)

Lonomia obliqua Walker, 1855, um saturnídeo exclusivamente americano (Lemaire 1972), vem desde 1989, sendo encontrado em plantas frutíferas comuns, em domicílios de regiões rurais do Sul e Sudeste do Brasil (Lorini, 1999). De colorido marrom com listras negras longitudinais e cerdas verde musgo, as lagartas de hábito gregário, confundem-se com os troncos das árvores fazendo com que as pessoas acidentalmente toquem-nas. Após a introdução de suas cerdas na pele humana, ocorre a liberação de uma toxina que produz distúrbios hemorrágicos (Duarte et al., 1990). Dependendo da gravidade, o veneno pode levar o indivíduo à morte, diferenciando-se dos sintomas causados pela maioria das "taturanas" (Cardoso, 1992).

No Brasil, esses acidentes já eram conhecidos da área médica, na década de 80, envolvendo seringueiros da área rural do Amapá (Fraiha et al., 1986). Naquela região, as lagartas de Lonomia são popularmente conhecidas por "Beiju-de-tapurú-de-seringueira". Na Venezuela, na mesma década, 
Arocha-Piñango et al. (1981) estudaram acidentes semelhantes onde o agente etiológico era Lonomia achelous, o mesmo do Amapá.

A partir de 1989 foram relatados centenas de casos hemorrágicos e óbitos, por contato com lonomias, no Rio Grande do Sul e Santa Catarina. Nestas regiões, são popularmente conhecidas por "Lagarta-taturana", "Oruga" ou "Ruga" , sendo o agente causador dos acidentes, lagartas de Lonomia obliqua . Verificou-se também a presença de lonomias no Estado de São Paulo na mesma época.

Devido à falta de um medicamento específico para o tratamento da síndrome hemorrágica, nasceu a idéia da produção de um soro. Utilizando as cerdas de L. obliqua de último instar, o Instituto Butantan produziu experimentalmente, em 1994, o soro antilonômico (Dias da Silva et al., 1996) que hoje, comprovada sua eficácia, faz parte do cronograma de soros do Ministério da Saúde, com produção anual de 6.000 ampolas. Atualmente o número acumulado de acidentes hemorrágicos no Sul e Sudeste do Brasil, ultrapassa a casa dos mil.

O crescimento atípico de colônias de lonomias teve seu pico no ano de 1998, ocasião em que o Instituto Butantan recebeu no período de novembro a abril, 40.000 lagartas procedentes dos três estados do Sul.

O aumento significativo da população de lonomias gerou várias hipóteses sem contudo terem sido explicadas em estudos mais aprofundados. Basicamente, alguns aspectos sempre foram comentados e nunca comprovados como por exemplo, a possível falta de inimigos naturais devido a excessiva utilização de agrotóxicos e o desmatamento contínuo de grandes áreas para diversos fins.

Dada a importância deste lepidóptero como causador de acidentes hemorrágicos somados à falta de explicações sobre o aumento da população de lagartas é que se deu a elaboração deste trabalho com o objetivo de reconhecer os seus inimigos naturais e investigar e conhecer os possíveis 
fatores que desencadearam o aumento populacional da espécie. Os aspectos estudados, principalmente com relação aos controladores biológicos, poderão no futuro auxiliar no desenvolvimento de um programa de controle biológico. 


\section{REVISÃO DE LITERATURA}

Os estudos sobre Lonomia spp. despertaram maior interesse, a partir de acidentes com essas lagartas na Venezuela, causando fibrinólise em humanos (Arocha-Piñango 1969). Os trabalhos na grande maioria referem-se aos aspectos fisiopatológicos do envenenamento; bioquímica do veneno; relato de casos e tratamento dos acidentados. Maior incremento nas pesquisas sobre esses mesmos assuntos, se deu no final da década de 80 , por ocasião de surtos de acidentes por L. obliqua no Sul e Sudeste do Brasil.

Dados relativos a bioecologia de lonomias são desconhecidos. As poucas citações brasileiras sobre aspectos biológicos restringem-se a ocorrência de lonomias em plantas diversas. Estudos dirigidos à taxonomia do grupo também são poucos, destacando-se entre esses as revisões feitas por Michener (1952) e Lemaire (1972).

\subsection{Biologia, morfologia, distribuição geográfica, plantas hospedeiras e sistemática}

Uma das mais antigas referências brasileiras, é de Mabilde ${ }^{1}$, citado por Silva et al. $(1967,68)$, onde é relatada a presença de Lonomia cynira, no estado do Rio Grande do Sul em 1896. Segundo os autores, trata-se de um guia prático para principiantes e colecionadores de insetos, contendo a descrição fiel de aproximadamente 1000 borboletas com 180 figuras.

\footnotetext{
${ }^{1}$ Mabilde A. P. Guia prático para os principais colecionadores de insetos. Porto Alegre: Gundlach \& Schuldt, 1896. 238p.
} 
Observa-se na revisão da bibliografia, a confusão, quanto à posição sistemática das lonomias, valendo tal fato tanto para gênero e espécies como também para família. Lima (1922) classificou Lonomia cynira, como lepidóptero pertencente a família Lasiocampidae, e ainda fez um comentário realçando o fato de que as espécies do gênero Lonomia, deveriam constituir a família Lonomidae à parte. Nesta mesma obra, é assinalada a presença de L. cynira nos estados do Rio de Janeiro e Espírito Santo, em folhas de Urticaceae (urtiga comum, urtiga vermelha e urtigão)

Baseado em exemplares coletados no Estado de Minas Gerais, a grande maioria em Viçosa, Hambleton \& Forbes (1935) publicaram uma lista de lepidópteros, onde é citada a presença de Lonomia achelous Cramer, 1920; L. achelous f. vulpina Draudt, 1922; L. achelous f. carnica Schaus, 1918 e L. cynira Cramer, 1931, sendo que esta última espécie se alimentando de folhas de Aroeira (Anacardiacea.). Neste trabalho, os autores agruparam os saturnídeos em duas subfamílias: Hemileucinae e Saturninae, citando os primeiros como mais comuns na América do Sul, e providos de cerdas urticantes tais como, Automeris, Dirphia e Hylesia . Não fazem nenhuma menção especial às lonomias.

Monte $^{2}$, citado por Lima (1936), aponta a presença de L. achelous (Crammer, 1777) em peroba manteiga, nos estados de Minas Gerais e Santa Catarina. Segundo Lemaire (1972), esta identificação está incorreta, tratando-se na realidade exemplares de Lonomia (Lonomia) obliqua Walker.

Schlottfeldt (1944) assinala também L. cynira em Aroeira, em ViçosaMG, colocando-a na família Lonomiidae.

Estudando insetos do Rio Grande do Sul, Biezanko et al. (1949), relacionaram $L$. achelous Cramer (Lep. Saturniidae) se alimentando de folhas de pereira (Pyrus communis) e Corticeira (Erythrina cristagalli) em Pelotas, sul

\footnotetext{
${ }^{2}$ Monte, O. Apontamentos para o conhecimento da biologia de alguns lepidópteros. O Campo, v.6, n.1, p.26-29, 1935.
} 
do estado. Também neste caso, Lemaire (1972) corrige a identificação para $L$. obliqua.

A revisão da família Saturniidae do Hemisfério Oeste, foi feita por Michener (1952), situando o gênero Lonomia na subfamília Hemileucinae, tribo Hemileucini, com dois subgêneros: Lonomia (Lonomia) Walker e Lonomia (Periga) Walker, ambos ocorrendo do México ao Brasil. O trabalho de Michener é completo, trazendo descrição de novas espécies, morfologia comparativa, paralelismos, filogenia, distribuição e classificação através de chaves dicotômicas. Infelizmente não há detalhes sobre as lagartas.

Lonomia cluacina Druce, 1877 foi encontrada em folhas de cafeeiro no Rio de Janeiro e Lonomia falcata submaculata Walker, 1855 em folhas de anda-açú e caquizeiro, na região de Guaratiba, RJ. Ambas citações são de Silva et al. (1968).

Um grande passo para o conhecimento do gênero Lonomia se deu através da obra de Lemaire(1972). O autor forneceu por intermédio da revisão do gênero, aspectos biológicos, morfológicos, taxonômicos e distribuição geográfica das oito espécies do subgênero Lonomia e dezoito espécies do subgênero Periga, com base em exemplares depositados em coleções. Cita o autor a presença de L.obliqua no Brasil, nos seguintes estados: Rio de Janeiro, Minas Gerais, São Paulo, Paraná, Santa Catarina, Rio Grande do Sul, Espirito Santo e Brasília. O trabalho de Lemaire é sem dúvida excelente ferramenta para o conhecimento de lonomias adultas, porém com poucos detalhes sobre a fase larval, restringindo-se superficialmente aos aspectos morfológicos. O autor comenta em sua obra, sobre as propriedades tóxicas do líquido secretado pelos espinhos da lagarta de Lonomia achelous que foram estudados por ArochaPiñango (1969), causando hemorragias após o contato das cerdas com a pele humana. Lemaire posiciona o gênero Lonomia como pertencente a família Attacidae. 
D' Antonio (1983) dissertou sobre a biologia, nutrição quantitativa e danos em cafezais do Sul de Minas Gerais por Lonomia circunstans, a partir de 1975. Neste trabalho, são realçados pelo autor, os desequilíbrios ocorridos na região de estudo, devido à utilização abusiva de produtos químicos, destruindo os inimigos naturais de L. circumstans .

D'Abrera (1995) publicou um trabalho sobre os saturnídeos, baseado nas coleções do British Museum ; segundo o autor, não se trata de uma revisão taxonômica e sim uma narrativa sobre a sistemática dos Saturnídeos. Neste trabalho com ilustrações coloridas dos espécimes adultos, o autor separa as lonomias em dois gêneros: Lonomia e Periga, discordando, da classificação de Lemaire (1972) onde as espécies são distribuídas nos subgêneros Lonomia e Periga.

Becker et al. (1996) registraram as lonomias como: Lepidoptera , Saturniidae , Hemileucinae, gêneros Lonomia e Periga.

O ciclo biológico de Lonomia obliqua foi observado em laboratório por Moraes (1997) citando como alimentação das lagartas, folhas de Tapiá (Alcornia sp.), planta nativa, encontrada em matas do Estado de São Paulo.

Lorini (1999) realizou um trabalho, visando o conhecimento dos aspectos biológicos e morfológicos sobre $L$. obliqua, através de exemplares coletados no campo e criados em laboratório.

Quanto à morfologia e fisiologia da glândula de veneno de L.obliqua pouco se sabe. Pesquisas recentes, e ainda não publicadas, atribuem a produção da toxina a uma glândula situada no ápice das espículas dos scoli, que por ocasião da introdução no tecido humano liberaria o veneno. Esta forma de inoculação baseia-se no trabalho de Barth (1954), que verificou tal fato em Automeris sp., um saturnídeo próximo a Lonomia. Outros pesquisadores atribuem a produção do veneno através de tecidos especializados, sem posição definida. Veiga (2001) . 


\subsection{Acidentes hemorrágicos}

Alvarenga (1912) apresentou um caso de contato humano com "taturana", em Minas Gerais, onde um indivíduo desenvolveu hemorragia. O acidente era semelhante aqueles observados atualmente, porem, o autor não forneceu detalhes sobre o inseto, visto não ser este o objetivo principal da tese. Talvez, tenha sido o primeiro caso de hemorragia por contato com Lonomia, citado na literatura médica.

Ihering (1914), em trabalho sobre "tatoranas", descreveu os acidentes mais comuns com lagartas de lepidópteros, com ênfase nos megalopigídeos, mencionando superficialmente $\mathrm{o}$ acidente relatado dois anos antes por Alvarenga. Citou ainda, o fato dos poucos estudos existentes, relacionados aos venenos desses animais.

De 1978 a 1984 foram relatados 26 casos hemorrágicos e 12 óbitos em humanos, causados pelo contato das cerdas de Lonomia aquelous provenientes do sudeste do Amapá e noroeste da ilha de Marajó (Frahia et al., 1986). As lagartas referidas se alimentavam de folhas de seringueira (Hevea brasiliensis) e quando em repouso no tronco, podiam ser observadas facilmente em "placas" que popularmente eram conhecidas por "beijus-de-tapuru-deseringueira". Apesar do trabalho estar voltado para a epidemiologia e clínica dos casos hemorrágicos, os autores forneceram dados da biologia e morfologia de $L$. achelous , incluindo foto da genitália do macho.

Acidentes semelhantes ocorreram na Venezuela e foram estudados por Arocha-Piñango et al.(1969). A identificação das lagartas envolvidas nos acidentes do Amapá e Venezuela, foi feita por Lemaire (1972).

A partir de 1989 inúmeros acidentes hemorrágicos em humanos aconteceram, desta vez no Estado do Rio Grande do Sul, mais especificamente centralizados em Passo Fundo e municípios próximos. Os agentes causadores eram lagartas de Lonomia obliqua . 
A insuficiência renal aguda após contato com as cerdas de lonomias foi citada por Duarte (1990).

Na região Sudeste também ocorreram acidentes hemorrágicos graves, por contato com cerdas de Lonomia obliqua, nos municípios de Mairinque (Burdmann et al., 1996) e Mogi das Cruzes (Fan et al. 1998). Através de levantamento realizado pelo Hospital Vital Brazil do Instituto Butantan e ainda não publicado, sabe-se atualmente da ocorrência de acidentes por lonomias e a presença das mesmas, em vários municípios do Estado de São Paulo.

\subsection{Bioquímica e Fisiopatologia do envenenamento}

Após o trabalho pioneiro de Arocha-Piñango (1967) outros o sucederam, destacando aqueles realizados no Instituto Butantan sobre Fisiopatologia do envenenamento (Kelen et al. 1995). Em recente descoberta, Reis et al. (1999), isolaram uma proteína do veneno de L.obliqua (Lopap) que apresenta propriedades com capacidade de dissolver trombos. Num futuro próximo os autores esperam produzir um fármaco com essa proteína, capaz de auxiliar na reversão de casos de trombose.

\subsection{Lonomias e o meio ambiente}

São inexistentes artigos relacionando lonomias com seu meio ambiente. A revisão bibliográfica sobre este assunto foi basicamente aquela referente ao conhecimento da geografia das regiões de ocorrência das lagartas. Dados gerais sobre a formação dos municípios envolvidos, visando o conhecimento das condições bióticas e abióticas, para o entendimento de possíveis mudanças ambientais foram também levantados. Foram consultados para esses fins, Oliveira (1990 a,b), IBGE (2000 a,b) e IBGE (2001 a,b). 


\subsection{Inimigos Naturais}

A primeira citação sobre um inimigo natural foi feita por Lima $^{3}$, citado por Silva et al. (1967) onde registrou Tapajohoughia sp. (Diptera, Tachinidae), em Lonomia sp., sobre Eucalyptus no município de Petrópolis RJ.

Gallo et al. (1988) citaram como inimigos naturais de L. circunstans, taquinídeos do gênero Hemisturmia e braconídeos do gênero Apanteles.

Moraes et al. (1992) citaram a presença de dois inimigos naturais de Lonomia sp. em exemplares procedentes de Chapada - RS e Chapecó-SC. Eram estes, exemplares de Diptera, Tachinidae e Hymenoptera, Ichneumonidae. As larvas dos dípteros impediam o prosseguimento do ciclo biológico da lagarta na passagem para pupa e as larvas dos himenópteros se alimentavam das estruturas internas, perfurando-as através do tegumento.

Lorini (1999) identificou como inimigos naturais de L. obliqua dois dípteros tachinídeos - Belvosia viedemanni Aldrich, 1928 e Leschenaultia sp. e um himenóptero, Enicospilus sp. (Ichneumonidae). Sobre esses parasitóides, o autor realçou o fato da necessidade de um estudo mais aprofundado para se verificar o potencial do controle biológico de Lonomia obliqua.

\footnotetext{
${ }^{3}$ Lima, A.M.C. Entomófagos sul americanos (parasitos e predadores) de insetos nocivos a agricultura. Boletin da Sociedade Brasileira de Agronomia, Rio de Janeiro. v. 11, n. 1, p.1-32, 1949.
} 


\section{MATERIAL E MÉTODOS}

Os experimentos deste trabalho foram realizados no Laboratório de Parasitologia do Instituto Butantan, São Paulo, e as coletas em municípios do extremo Oeste de Santa Catarina, Norte do Rio Grande do Sul e Sudoeste de São Paulo, no período de novembro de 1997 a abril de 2001.

\subsection{Obtenção das lagartas de Lonomia obliqua}

Para coleta e manutenção das lagartas em cativeiro, seguiu-se a metodologia básica utilizada por Lorini (1999), D'Antonio (1983), Moraes (1980/81), e Parra (1990) aplicando-se modificações quando necessárias.

As lagartas de $L$. obliqua foram obtidas em coletas nos estados de São Paulo, Santa Catarina e Rio Grande do Sul (AnexoA)

O método de captura utilizado foi manual, deslocando-se as lagartas dos troncos das árvores com pinças ou instrumentos improvisados com gravetos e acondicionando-as em caixas de madeira ou recipientes de vidro de tamanho variado. As coletas ocorreram nos períodos da manhã e da tarde, nos meses de novembro a maio (Figuras 1 e 2 ). $O$ fato dos contatos acidentais com lagartas de Lonomia ocorrerem sempre com exemplares de $6^{\circ}$ instar, por estarem próximos à fase de pupa, e portanto próximos ao chão, fez com que as pessoas localizassem com certa facilidade os bandos de lagartas, colaborando nas coletas. 


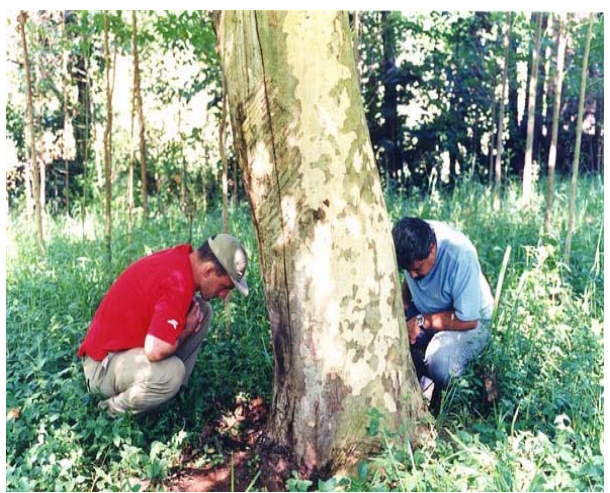

Figura 1 - Coleta em São Miguel do Oeste - SC.

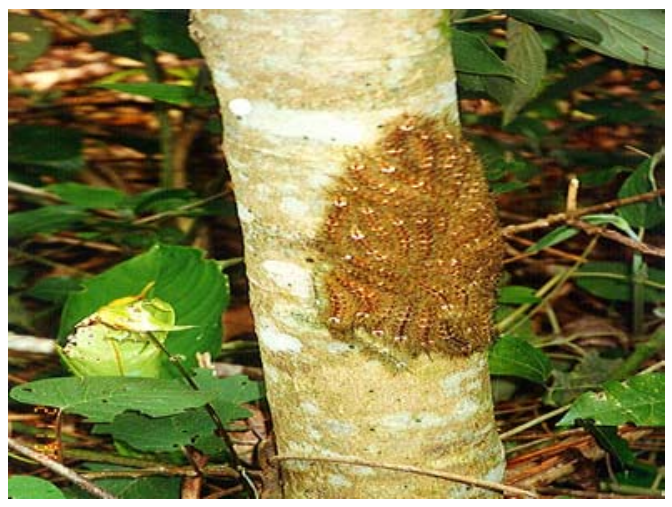

Figura 2 - Lonomias coletadas em Ibiúna - SP

Após as coletas os espécimes foram separados, dando-se preferência aqueles de $5^{\circ}$ e $6^{\circ}$ instares, devido a abundância, e por resistirem melhor as condições de laboratório. Parte do material foi utilizado também na produção do soro antilonômico produzido no Instituto Butantan.

\subsection{Envio, recebimento e manutenção das lagartas em laboratório,}

O material coletado nos estados do Sul do Brasil, foi enviado ao Instituto Butantan por via aérea, em caixas padronizadas de madeira, medindo $40 \mathrm{~cm} \times 30 \mathrm{~cm} \times 20 \mathrm{~cm}$, contendo na tampa pequenos orifícios para arejamento (Figura 3). Nessas localidades, os colaboradores responsáveis pelas coletas foram orientados para acondicionar aproximadamente 200 lagartas por caixa, com poucas folhas da planta hospedeira, para que não ocorresse excesso de umidade, prejudicando assim as lagartas.

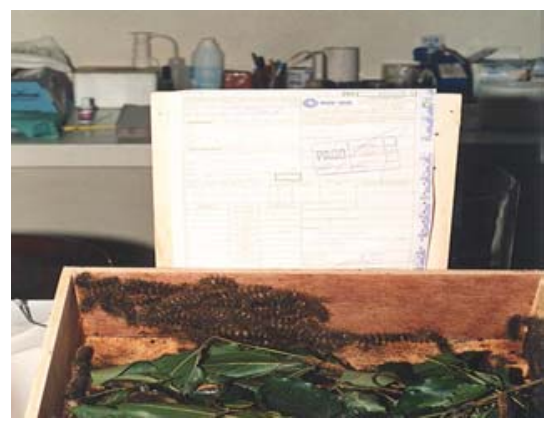

Figura 3 - Caixa padronizada para remessa aérea 
Em São Paulo, devido à proximidade dos locais de coleta com o Instituto Butantan, os recipientes variaram desde frascos comuns de vidro até caixas de papelão de tamanhos e formas diversas. As coletas em S. Paulo, foram realizadas na maioria das vezes por moradores dos locais de ocorrência e trazidos ao Instituto Butantan logo em seguida ao achado.

No Laboratório de Parasitologia do Instituto Butantan, novamente os exemplares foram separados criando-se dois grupos: lagartas sadias para criação e lagartas doentes para obtenção de inimigos naturais (Figura 4).

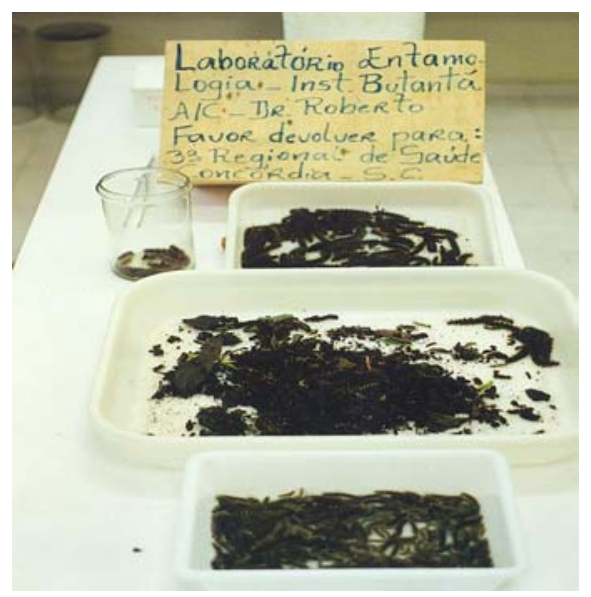

Figura 4 - Triagem do material

\subsection{Criação}

O objetivo desta criação foi o acompanhamento do desenvolvimento das lagartas sadias coletadas no campo, para a verificação de possíveis inimigos naturais e acompanhamento do ciclo biológico.

As lagartas de $5^{\circ}$ e $6^{\circ}$ instares sadias foram acondicionadas em criadouro de acrílico medindo $120 \mathrm{~cm} \times 60 \mathrm{~cm} \times 60 \mathrm{~cm}$ (glove box adaptado), com tampa superior e aberturas circulares teladas, e removíveis na parte anterior para manejo dos espécimes (Figura 5). 


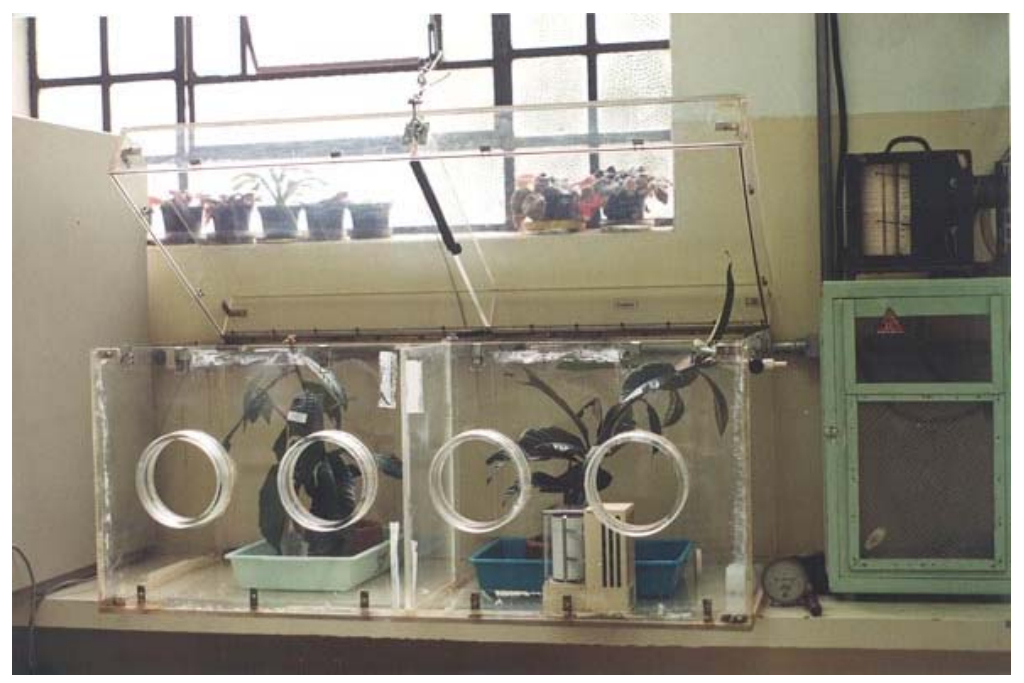

Figura 5 - Glove Box adaptado para criadouro

A alimentação oferecida as lonomias constituíu-se de folhas de Nespereira, Abacateiro e Tapiá (Alchornia sp.), sendo esta última nativa na região Sudeste e encontrada em abundância no Instituto Butantan. As folhas alimentícias foram lavadas em água corrente antes de serem oferecidas às lagartas. As condições de temperatura, umidade e fotoperíodo na sala de criação foram em média de $20^{\circ} \mathrm{C}$, umidade relativa de $80 \%$ e fotofase de $12 \mathrm{~h}$. As lagartas sadias atingiram as fases de pupa e adulto, sem apresentarem inimigos naturais (Figura 6).
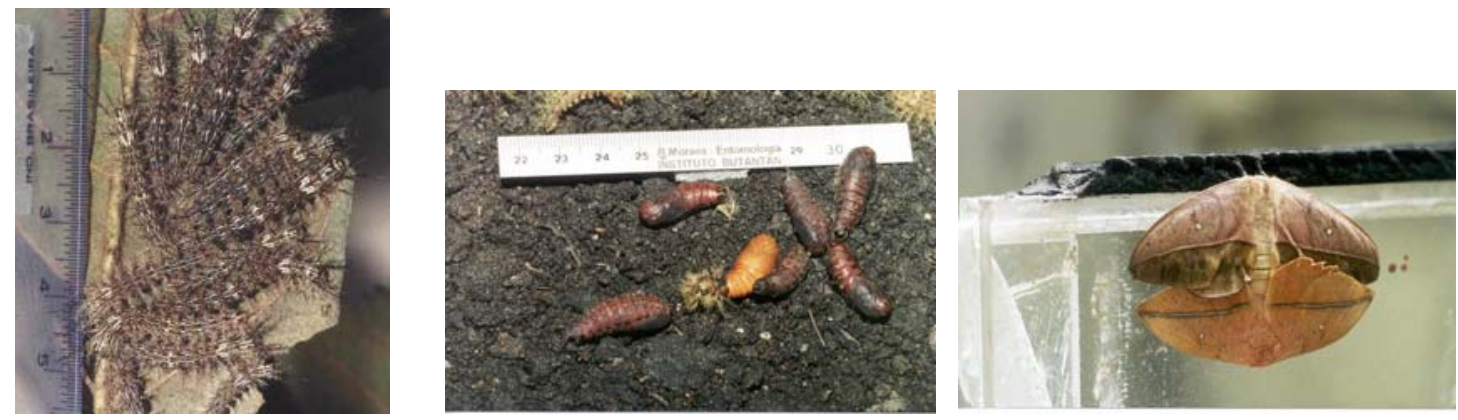

Figura 6 - L.obliqua . Lagartas(E), pupas (C) e adultos em cópula (D) no criadouro de acrílico 
Os adultos obtidos foram colocados em criadouro ao ar livre no Horto Oswaldo Cruz do Instituto Butantan. Este criadouro de madeira medindo $60 \mathrm{~cm} \mathrm{x}$ $60 \mathrm{~cm} \times 60 \mathrm{~cm}$, telado nas 5 faces foi mantido suspenso a uma altura de $4 \mathrm{~m}$ onde os recém-emergidos foram introduzidos (Figura 7).

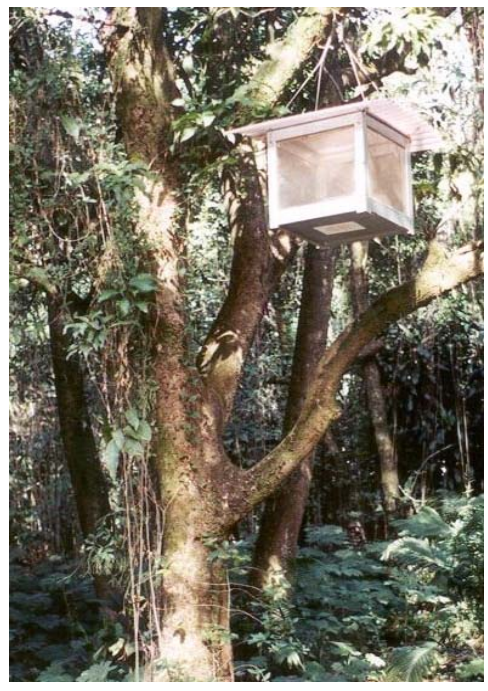

Figura 7- Criadouro suspenso no Horto Oswaldo Cruz - Instituto Butantan

Optou-se por utilizar um criadouro suspenso na mata, pelo fato dos espécimes poderem se desenvolver o mais próximo possível das condições naturais.

Após as cópulas, iniciaram-se as posturas (Figura 8) depositadas em todas as partes do criadouro, com preferência nas superfícies com ângulos. As paredes internas do criadouro foram revestidas de fita crepe para fácil coleta das posturas. As posturas foram acondicionadas em recipientes de plástico, até próximo da eclosão das lagartas, que foram transferidas para as folhas da planta hospedeira e reintroduzidas no criadouro de acrílico dentro do laboratório (Figura 9) 


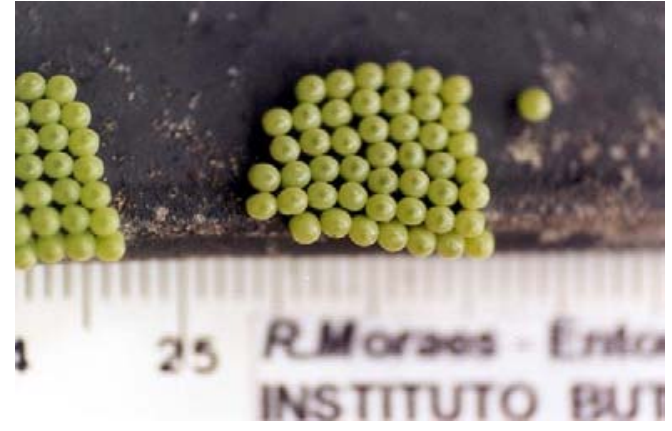

Figura 8 - Posturas de L. obliqua

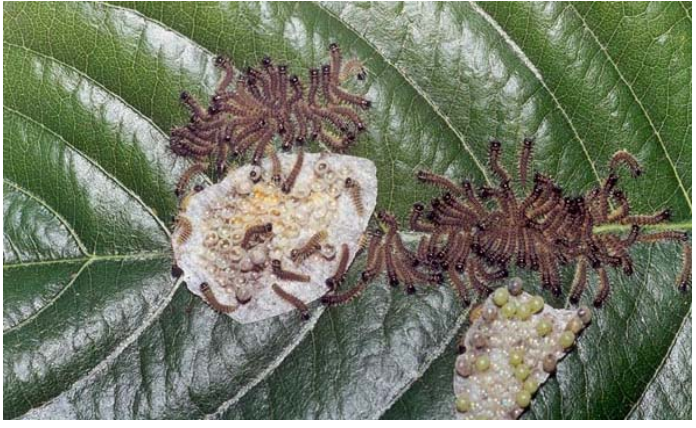

Figura 9 - Ovos e lagartas de $1^{\circ}$ instar de L. obliqua sobre a planta hospedeira

\subsection{Obtenção de inimigos naturais}

Para a obtenção dos inimigos naturais, foram selecionados os exemplares de $6^{\circ}$ instar que apresentavam letargia, turgidez, secreções e colorido diferenciado, sinais que indicam estado patológico em insetos (Steinhaus, 1949; Alves,1986). Pré-pupas com pouca movimentação e pupas mal formadas, também foram separadas (Figura 10).
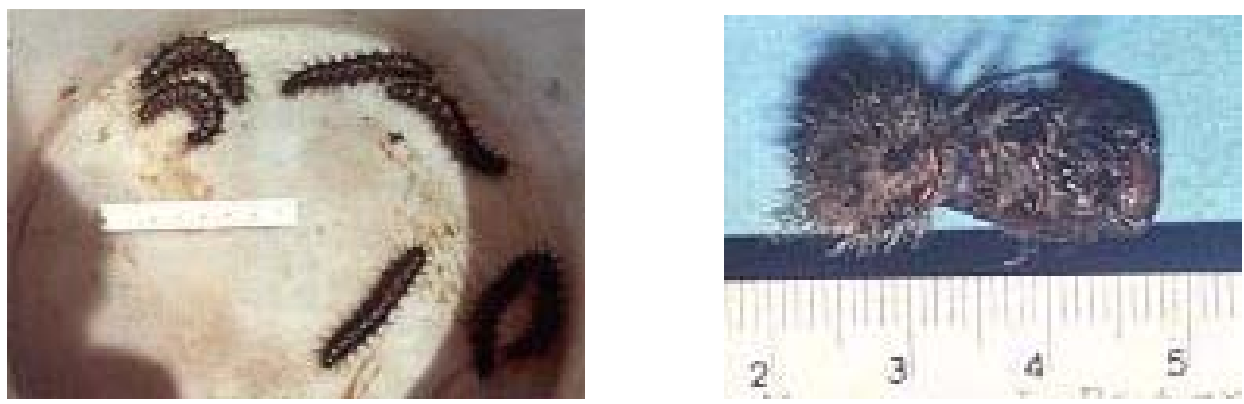

Figura 10 - Lagartas de L. obliqua com turgidez e secreção(E) e pupa mal formada(D) 


\subsubsection{Himenópteros}

Observou-se a movimentação e aspecto das lagartas letárgicas e túrgidas diariamente. Não se utilizou substrato na bandeja. Após 5 dias, constatou-se a presença de himenóptero parasitóide (Figura 11).

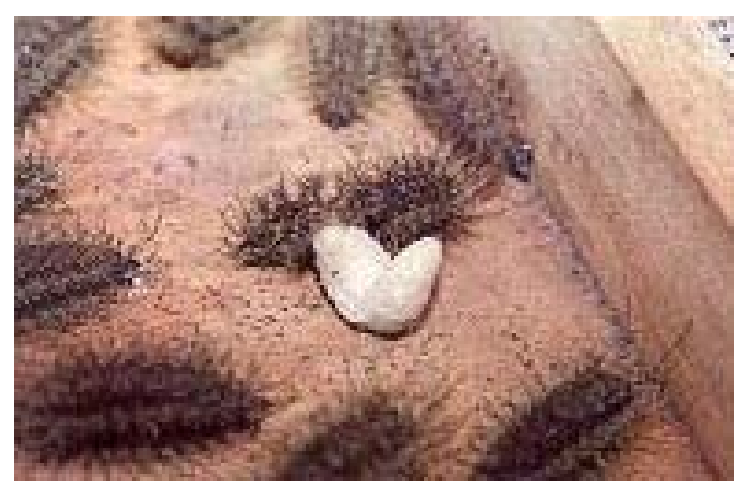

Figura 11- Lagarta de L.obliqua parasitada por himenóptero

A saída do parasitóide do hospedeiro se deu sempre no período entre 18:00h e 7:00h, após rompimento do tegumento da lagarta na região ventral. Obteve-se uma larva de himenóptero por lagarta. Após deixarem os hospedeiros as larvas foram colocadas em recipiente de acrílico, com vermiculita e folhas de ameixeira como substrato, em umidade de $80 \%$. As larvas teceram casulos e passaram a pupas. Os adultos obtidos foram sacrificados após expansão das asas e enviados para identificação.

\subsubsection{Vírus}

As lagartas com secreções (vômito), flácidas, colorido amarelado e principalmente posicionamento irregular ( suspensas por uma das falsas pernas e o corpo curvo), foram isoladas (Figura 12). 


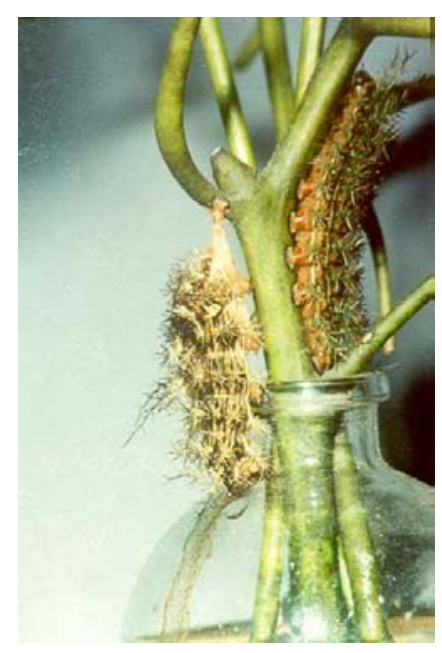

Figura 12 - Lagarta de L. obliqua (E) com sintomas de virose

No laboratório de Imunologia Viral do Instituto Butantan procedeu-se a metodologia apropriada (O’Reilly et al. 1992 e Batista 1986), que consistiu da maceração desses espécimes em solução tampão Tris-Bufer $(\mathrm{pH} \mathrm{7,4)}$ obtendose uma homogenização dos tecidos. Esse material foi diluído em água e filtrado em gaze. A filtração do homogenizado permitiu reter o tecido das lagartas, deixando passar o líquido rico em poliedros. Adicionou-se SDS (SódioDuodecil-Sulfato) e incubou-se por 50 minutos. Centrifugou-se em centrífuga refrigerada a 3000 rpm e os poliedros foram coletados do precipitado.

\subsubsection{Dípteros}

Lagartas escuras e letárgicas, pré-pupas com pouca movimentação e pupas mal formadas, foram colocadas em bandejas com vermiculita e mantidas em ambiente com umidade de $80 \%$, por meio de borrifação de água pela manhã e início da noite. As larvas dos dípteros romperam o tegumento das lagartas pelo lado dorsal, pupando posteriormente no substrato . (Figura 13). 


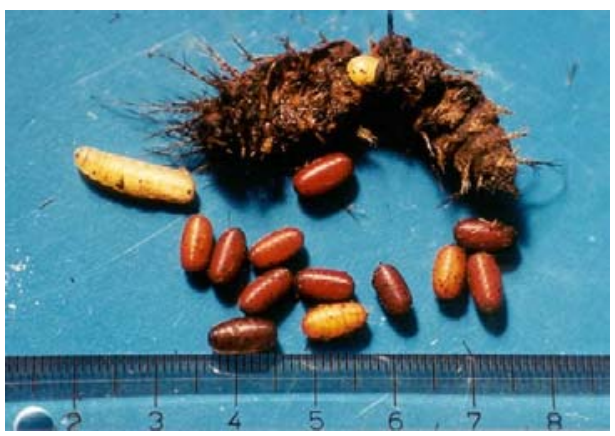

Figura 13 - Lagarta de L.obliqua parasitada por Díptero

As pupas de Lonomia foram rompidas pelas larvas dos dípteros também pelo lado dorsal, deixando as mesmas (Figura 14). Uma vez fora das pupas, as larvas se desenvolveram em substrato de vermiculita, em umidade de $80 \%$. Os dípteros obtidos foram sacrificados após desenvolvimento completo das asas e enviados para identificação.

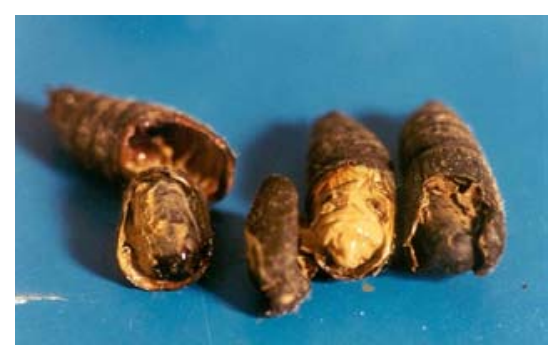

Figura 14 - Pupas de L.obliqua parasitadas por díptero

\subsubsection{Nematóide}

Numa remessa de 40 exemplares de L.obliqua procedente de Ibiúna SP, notou-se após adaptação as condições de laboratório a letargia nos movimentos de 15 exemplares. Notou-se também o colorido mais claro destas em relação ao resto do bando. Após 24 horas, deu-se a expulsão espontânea de 1 nematóide, de uma das lagartas. Outras lagartas restantes foram sacrificadas para a verificação de nematóides (Figura 15). 

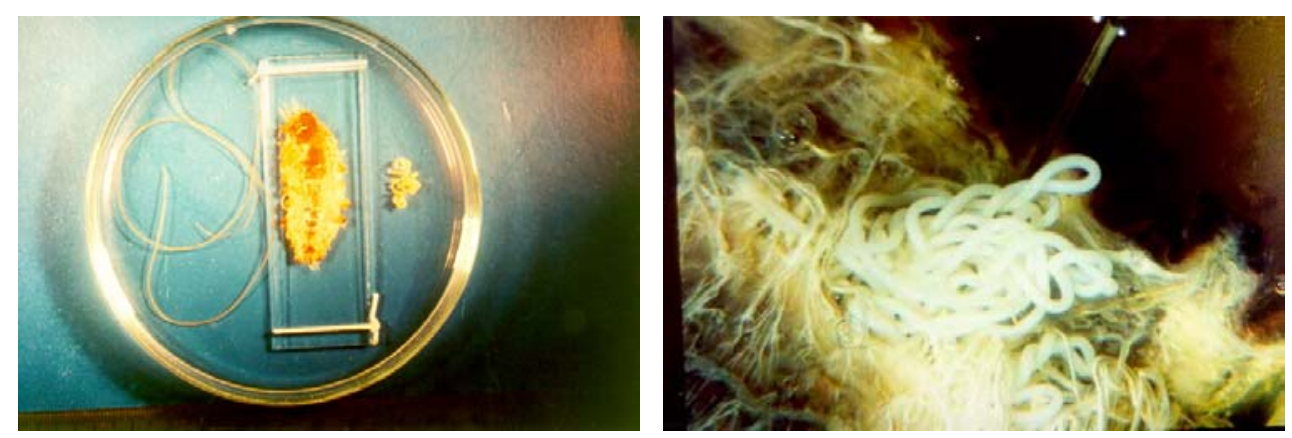

Figura 15 - Placa de Petri com nematóide expelido (E) e namatóide na hemocele de Lonomia obliqua (D)

Em Placa de Petri com fundo de parafina, realizou-se a dissecação sob lupa estereoscópica. Em corte longitudinal e ventral, com o espécime submerso em solução salina, foram sacrificados 5 exemplares, obtendo-se os nematóides da hemocele e do tubo digestivo. Devido a solução salina, os nematóides se mantiveram vivos, sendo possível registrar a movimentação dos mesmos em vídeo.

A fixação dos nematóides foi feita com formol a $10 \%$ com os exemplares prensados entre 2 lâminas conforme metodologia de Pessôa (1973).

\subsubsection{Hemíptero}

De um lote de lonomias procedentes do Paraná, observou-se a presença de um exemplar da família Pentatomidae, sugando uma lagarta. Os dois espécimes foram isolados em frasco plástico e observada a predação. Não foi possível o registro fotográfico. O hemíptero predou a lagarta , alternando a localização de sucção . O exemplar foi sacrificado, montado, e posteriormente identificado. 


\subsection{Região de estudo}

Duas viagens foram realizadas sendo uma para o estado do Rio Grande do Sul e outra para Santa Catarina, (Anexos C e D) com o objetivo de coletar e reconhecer o hábitat das lagartas. No estado de São Paulo (Anexo E), as observações in loco foram realizadas a partir de chamados sobre a presença das lagartas ou devido a ocorrência de acidentes com as mesmas, sem data previamente estipulada.

Nos estados do Sul, o encontro dos locais deu-se através de protocolo de pesquisa, aplicado pela equipe médica do Hospital Vital Brasil do Instituto Butantan (Anexo B ) e arquivo de ocorrências do Corpo de Bombeiros de São Miguel do Oeste. Ambos documentos proporcionaram além de dados clínicos do paciente, também a localização do domicílio.

Para a obtenção de dados históricos, geofísicos, bióticos e abióticos desses locais, foram consultados: Arquivo Histórico Regional de Passo Fundo, Museu Municipal de Carazinho, Museu Municipal de Chapecó, EMBRAPA de Passo Fundo, EPAGRI de Santa Catarina e IBGE.

Nas viagens verificou-se o hábitat atual das lagartas para posterior comparação destas condições em épocas passadas. Verificou-se também as características da vegetação, relêvo, e dados climáticos, e realizou-se um inquerito com a população local para saber de possíveis mudanças ambientais atuais e passadas- que caracterizassem algum desequilíbrio ambiental. Em todas as localidades foi questionada a utilização de agrotóxicos. 


\section{RESULTADOS}

Através da metodologia aplicada e de acordo com o principal objetivo proposto foi possível o reconhecimento dos seguintes inimigos naturais:

Parasitóide obtido de lagartas procedentes de: São Miguel do Oeste-SC, col. Secretaria de Saúde, data: jun, 2001; Mairiporã-SP, col. Secret. Saúde, data: ago, 2001; Concórdia-SC, col. Secret. de Saúde, data fev. 2001; Passo FundoRS, col. UPF, data: dez,1999

Ordem Hymenoptera, Família Ichneumonidae, Enicospilus Stephens 1835 (Figura 16). Material identificado no Dep. De Entomologia da ESALQ-Piracicaba

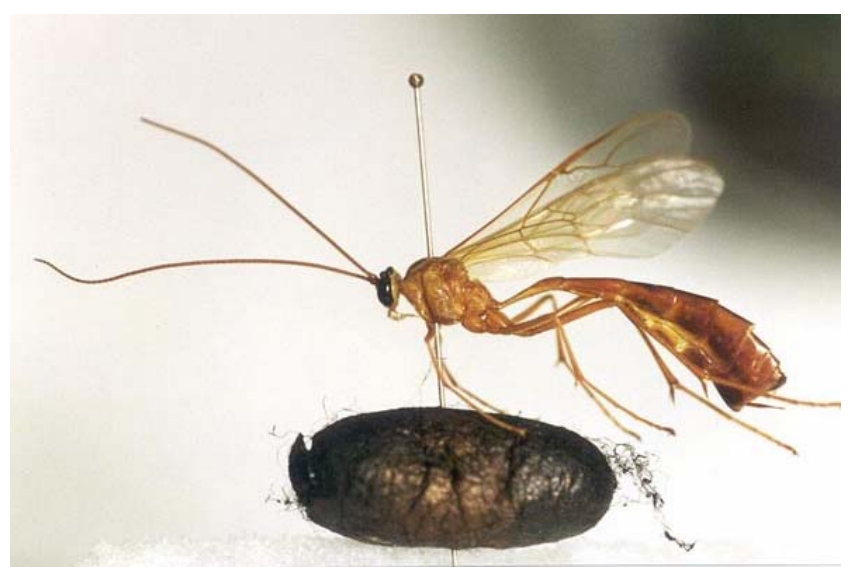

Figura 16 - Adulto e pupário de Enicospilus sp (Hymenoptera: Ichneumonidae) 
Parasitóide obtido de lagartas procedentes de: São Miguel do Oeste-SC, col. Secret. da Saúde, data: dez 1999. Ordem Díptera, Família Tachinidae, Subfamília Goniinae, Tribo Harrisiini, Moreiria wiedemanni sp.nov.(Figura 17) Identificação de Ronaldo Toma, Museu de Zoologia-USP-São Paulo

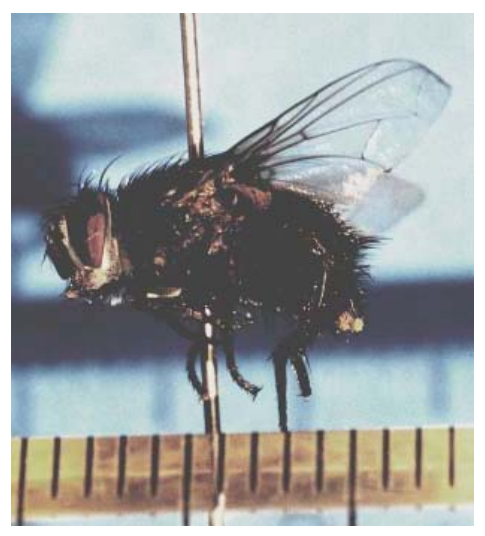

Figura 17 - Moreiria wiedemanni (fêmea) (Díptera: Tachinidae)

Parasitóide obtido de lagartas procedentes de São Miguel do Oeste, col. Corpo de Bombeiros de SM.Oeste, data: 21/06/2001. Ordem Díptera, Família Tachinidae, Subfamília Goniinae, Tribo Eryciini , Lespesia affinis (Townsend, 1927).(Figura 18) Identificação de Ronaldo Toma, Museu de Zoologia-USP, São Paulo

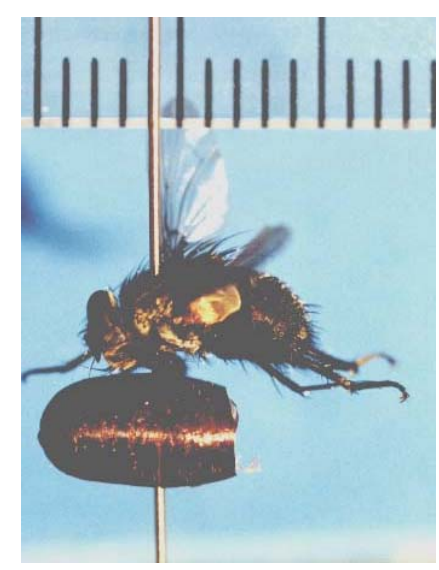

Figura 18 - Exemplar fêmea e pupário de Lespesia affinis (Tawns.,1927) (Díptera: Tachinidae) 
Parasitóide obtido de lagartas procedentes de Concórdia-SC, col. VI CARS, data: mar 1999. Ordem Díptera, Família Tachinidae, Subfamília Goniinae, Tribo Belvisiini , Belvosia Roboneau-Desvoidy, 1830 (Figura 19). Identificação de Ronaldo Toma, Museu de Zologia-USP, São Paulo

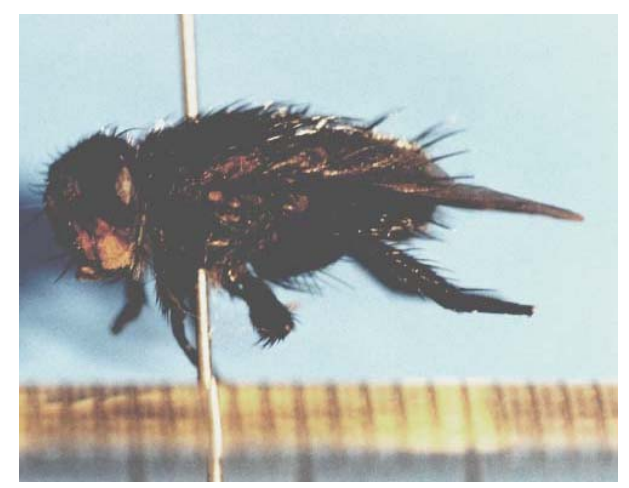

Figura 19 - Belvosia sp. (fêmea) (Díptera: Tachinidae)

Vírus (Figura 20) obtido de lagartas procedentes de São Miguel do Oeste, col. Corpo de Bombeiros de S.M.Oeste, data: nov.1999 . Identificado por José L. Wolff, Lab. de Imunologia Viral. Inst. Butantan.
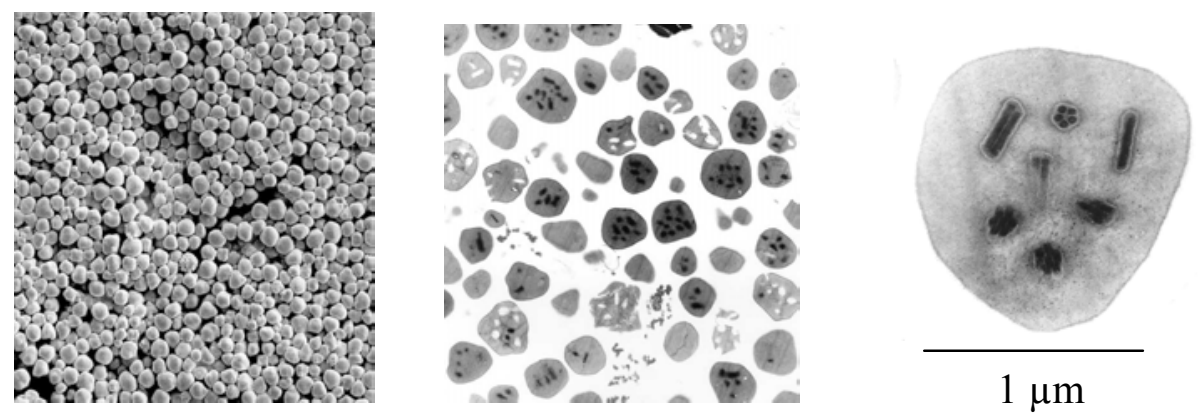

Figura 20 - Fotomicrografia de varredura (E), Fotomicrografia de Transmissão (M) e detalhe do poliedro (D) de LoobMNPV - Lonomia obliqua Multiplo Nucleopolyhedrovirus 
Parasita obtido de lagartas procedentes de Ibiúna-SP, col. Aruanda Ambiental, data: dez 1998. Nematóide: Phylum Nemathelminthes, Classe Nematoda, família Mermithidae, Hexamermis sp. (Figura 21). Material identificado por Luiz Carlos Camargo Barbosa, ESALQ-Piracicaba.

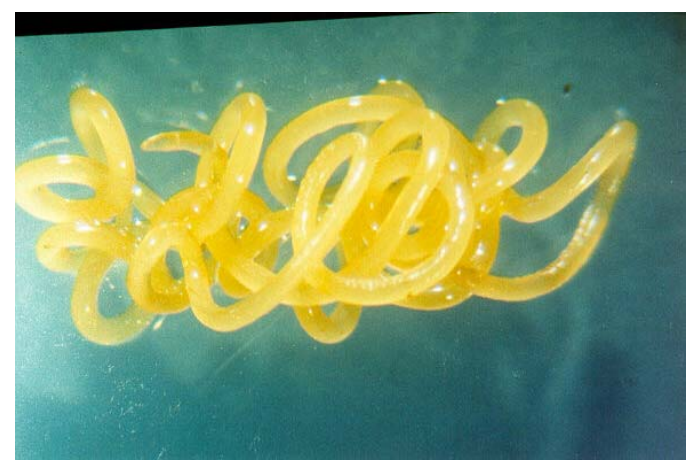

Figura 21- Exemplar de Hexamermis sp (Nematoda: Mermithidae) expelido de L. obliqua

Predador obtido junto a lagartas procedentes de Curitiba-PR, col. Secret. de Saúde, data: fev 1998 Ordem Hemíptera, Família Pentatomidae, subfamília Asopinae, Alcaeorrhynchus grandis (Dallas, 1851) (Figura 22). Material identificado no Lab. de Parasitologia do Instituto Butantan-SP
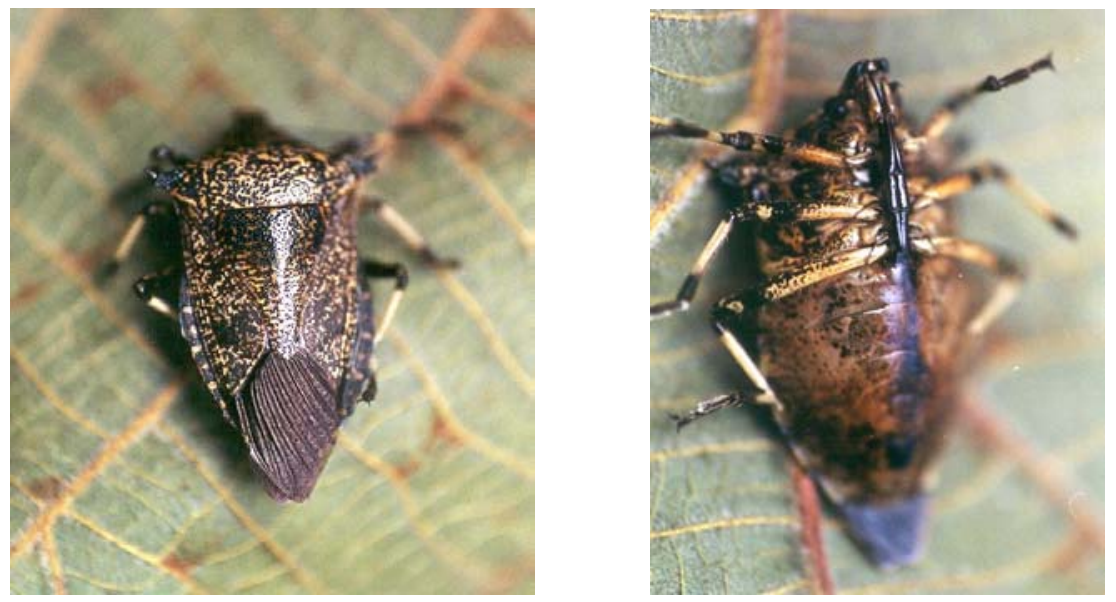

Figura 22 - Alcaeorrhynchus grandis (Hemiptera: Pentatomidae) predador de L. obliqua Vista dorsal(E). Vista ventral (D) 


\section{DISCUSSÃO}

Após 1989, ocasião em que teve início o aumento da população de lonomias em estados do Sul do Brasil, desencadeou-se uma série de especulações, impulsionadas pela curiosidade científica, para se entender meios e mecanismos do presente fenômeno. Foram debatidas em diversas reuniões científicas regionais as possíveis causas como, por exemplo, a migração de lonomias, do Norte do Brasil para o Sul, visto terem sido os primeiros acidentes por contato com essas lagartas ocorridos no Amapá (Frahia 1986 ).

Outra hipótese levantada foi a adaptação de lonomias a outras plantas hospedeiras. Assim, de alguma forma esta adaptação poderia causar modificações fisiológicas na espécie, alterando a composição da toxina, que em geral nos Saturnídeos, causa apenas reações dermatológicas sem gravidade após contato das cerdas em humanos,

No que diz respeito a primeira hipótese, sobre uma possível migração, pode-se descartá-la, devido a comprovada existência de lonomias em outras regiões do país, incluindo-se os estados do Sul e Sudeste desde a década de 20, como pode ser observado através de exemplares depositados na coleção entomológica do Museu de Zoologia da Universidade de São Paulo e Museu Fritz Plaumann em Seara, Santa Catarina. No Instituto Butantan, está depositado um exemplar adulto, fêmea, de Lonomia obliqua, coletado no Horto Oswaldo Cruz do próprio Instituto, em São Paulo, datado de 1972, comprovando desta forma a existência de L. obliqua, na capital do estado. Ainda relacionado à migração da espécie, soma-se o fato dos acidentes do 
Norte do Brasil, terem sido causados por Lonomia achelous, espécie diferente da que ocorre no Sul e Sudeste.

Com relação a adaptação da espécie a plantas que pudessem modificar a fisiologia do mecanismo de produção do veneno, nada até o presente momento foi verificado.

Excluindo-se estas e outras hipóteses, restam duas possíveis causas plausíveis para explicar o fenômeno. Uma delas seria a diminuição ou erradicação de algum inimigo natural e a outra seria o desmatamento verificado ao longo dos anos. De qualquer forma, a evidência dos fatos indica que a ocorrência de maior número de lonomias, deveu-se a algum desequilíbrio ecológico.

\subsection{Dípteros e himenóptero como Inimigos naturais de Lonomia obliqua}

Em se tratando do possível desaparecimento ou diminuição de inimigos naturais, fez-se necessário, num primeiro momento, conhecer e identificar esses inimigos tornando-se estes aspectos, os objettivos principais deste trabalho.

A identificação de parasitos protélicos, dípteros da família Tachinidae, traz uma considerável contribuição, visto que as espécies Moreiria wiedemanni, uma espécie nova (Toma 2001) e Lespesia affinis não haviam sido citadas como inimigos naturais de $L$. obliqua por outros autores.

Embora Belvosia tenha sido citada por Lorini ( 1999) como parasitóide encontrado em lonomias em Passo Fundo,RS, a descoberta de exemplares do mesmo gênero em espécimes de São Miguel do Oeste,SC, vem também contribuir para o conhecimento de uma nova localidade de ocorrência do parasitismo. O mesmo acontece com o himenóptero Enicospilus sp. (Ichineomonidae), também citado por Lorini (1999) no Rio Grande do Sul, identificado neste trabalho como parasitóide de $L$. obliqua, atuando no extremo Oeste de Santa Catarina e sudeste de São Paulo. 


\subsection{Vírus (NPV) como agente entomopatogênico de L. obliqua}

As lonomias observadas neste trabalho infectadas por NPV, foram aquelas procedentes de municípios do Oeste Catarinense. Observou-se que lagartas acondicionadas em algumas caixas de madeira, padronizadas para o transporte aéreo, quando recebidas no Laboratório de Parasitologia do Instituto Butantan apresentavam os sintomas comuns de virulência e outras lagartas acondicionadas em caixas idênticas continham exemplares perfeitamente sadios. Após contato com os fornecedores concluiu-se que devido a problemas de contenção de verbas para transporte terrestre, as lagartas de municípios mais distantes, foram acondicionadas todas em uma só caixa à medida que iam sendo coletadas. No final de um período que variou de três a dez dias, essas lagartas foram enviadas para a principal regional de saúde, em Chapecó-SC, e de lá enviadas por avião para São Paulo. Em contraposição, as lagartas coletadas em Chapecó e localidades limítrofes, apresentavam-se geralmente sadias.

Concluiu-se que as más condições no transporte das lagartas envolvendo longo tempo de traslado, temperaturas altas, número excessivo de espécimes por caixa e muitas vezes excesso de folhas e fezes, propiciou um ambiente desfavorável, causando stress e conseqüentemente baixa na resistência das lonomias. É sabido que a principal forma de contaminação das lagartas por vírus, se dá através da alimentação então, desta forma, as lonomias possivelmente contraíram a poliedrose nos seus locais de origem e devido as condiçõs estressantes tiveram a patogenicidade manifestada. $O$ poder patogênico desse vírus é bastante expressivo, dizimando em poucos dias várias colônias de lagartas, como pode ser observado no laboratório. $\mathrm{O}$ reconhecimento de LoobMNPV - Lonomia obliqua Multiplo Nucleopolyhedrovirus trás também sua contribuição ao estudo de patógenos de Lonomia visto que, o grupo de vírus da poliedrose nuclear (NPV) constitui um grupo muito promissor para utilização no controle microbiano de insetos (Alves, 1986). 


\subsection{Nematóide como parasita de L.obliqua}

Os nematóides associados a insetos tem recebido especial importância como agentes de controle biológico nos últimos anos. Eles tem sido encontrados associados com a maioria das ordens de insetos, envolvendo onze ordens de nematóides e dezenove ordens de insetos. Essas associações vão desde relações foréticas até o entomoparasitismo obrigatório que pode desenvolver no inseto parasitado, esterilidade, redução da fecundidade, atraso no desenvolvimento, aberrações e a morte do hospedeiro. Entre os Nematoda da classe Adenophorea são os representantes da família Mermithidae os que mais se destacam como parasitas de insetos, tendo sido obtidos representantes dessa família em Helicoverpa zea e Galleria mellonella sendo Hexamermis sp. o nematóide parasita de H. zea (Technical Bulletin,2002).

A obtenção de Hexamermis sp.em Lonomia obliqua é inédita, pouco se sabendo de maiores detalhes sobre este parasitismo. Os espécimes obtidos em lonomias ocuparam sempre o tubo digestivo (Figura 23) na proporção de um nematóide por lagarta.

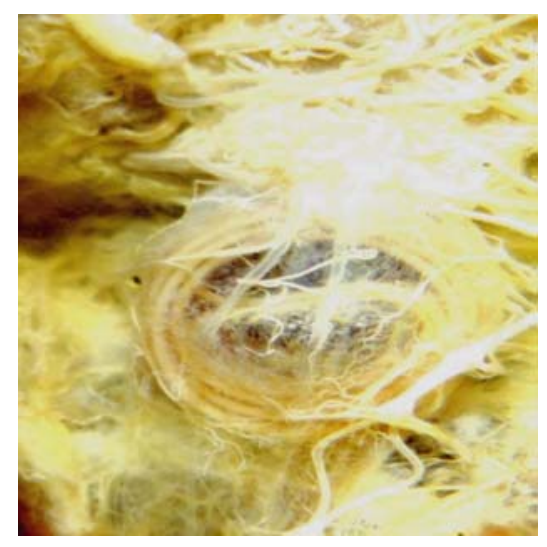

Figura 23 - Hexamermis sp. dentro do tubo digestivo de L.obliqua

Não foi possível o acompanhamento da biologia de Hexamermis sp. visto que as lonomias foram sacrificadas para a coleta dos nematóides. 
Presume-se que a infestação do parasita se deu por ingestão através da planta hospedeira. $\mathrm{O}$ encontro de um exemplar de Hexamermis sp. próximo a uma Lonomia naturalmente morta, induz ao fato de que o parasita conclui seu ciclo de vida fora do hospedeiro . Reforça esta hipótese o fato de que todos os exemplares obtidos por dissecção das lagartas eram jovens. Mesmo sabendose das dificuldades em obter-se nematóides de forma massal, para controle biológico, a ocorrência inédita de Hexamermis sp. em lagartas de L. obiqua , abre caminho para o estudo da possível utilização deste nematóide como agente de controle biológico (Alves, 1986).

\subsection{Predação de L.obliqua por Hemíptera, Heteroptera}

Os hemípteros heterópteros da família Pentatomidae, se alimentam de vegetais porém, membros da subfamília Asopinae são predadores, particularmente sobre lagartas de lepidópteros (Richards, 1997).

As espécies mais interessantes, segundo Lima (1940), são, Oplomus (Catostyrax) catena predador de lagartas de Actinote pellenea (Acraeidae); Apateticus (Eupodisus) mellipes e Alcaeorrhynchus grandis, predadores de lagartas de Dione juno (Heliconiidae). Este mesmo autor, cita ainda a predação de A. grandis sobre lagartas de Papilio thoanthoides, (Papilionidae), Megalopyge urens (Megalopygidae) e Automeris coresus (Saturniidae).

Pouco se sabe sobre a biologia deste predador. Em pesquisas mais recentes Richman et al. (1978) criaram A. grandis em condições de laboratório verificando, em média, o período de 60 dias de ovo à adulto. Embora sejam escassos os trabalhos sobre $A$. grandis a espécie tem sido apontada como importante predadora de pragas de soja na Flórida (Predatory stink bug,2002)

Nenhuma citação sobre a predação de $A$. grandis sobre Lonomia obliqua foi feita até o presente momento. $O$ encontro deste asopíneo predando exemplares procedentes de Curitiba,PR é inédito. Dada a falta de maiores conhecimentos sobre a predação de lonomias, se faz necessário um estudo 
mais aprofundado visando ao conhecimento da capacidade predatória e a possível utilização deste hemíptero em controle biológico.

\subsection{Aspectos bióticos e abióticos das regiões de ocorrência de L.obliqua}

As regiões de maior ocorrência de lonomias situam-se entre as coordenadas $26^{\circ} 35^{\prime} 50^{\prime \prime} S$ e $53^{\circ} 31^{\prime} 50^{\prime \prime}$ W (São Miguel do Oeste -Extremo Oeste de Santa Catarina) e $28^{\circ} 15^{\prime} 39^{\prime \prime} S$ e $52^{\circ} 24^{\prime} 32^{\prime \prime}$ W ( Passo Fundo -Norte do Rio Grande do Sul) (Anexo A).

A altitude média é de $554 \mathrm{~m}$ em relação ao nível do mar, com limites em Romelândia e Erval Sêco (425 m) e Passo Fundo (687 m). A temperatura oscila entre $0^{\circ}$ e $38^{\circ} \mathrm{C}$ com média anual de $18^{\circ} \mathrm{C}$.

A vegetação atual é predominantemente caracterizada por policulturas, destacando-se em Passo Fundo, a cultura da soja, que atinge 35000 hectares de área plantada (IBGE 2000). As culturas temporárias e permanentes de São Miguel do Oeste e Passo Fundo,RS, estão relacionadas nos anexos G, $\mathrm{H}$ e I.

A região na grande maioria é composta de pequenas propriedades onde cultivam-se frutas em pomares próximos as residências. Nesses locais se dá a presença de lonomias. Segundo Lorini (1999), a partir de 1990 foram identificadas as seguintes plantas hospedeiras de L.obliqua : cedro (Cedrella fissilis); figueira (Fícus carica); Seringueira (Ficus elastica); Figueira-do-mato (Ficus subtiplinervia); abacateiro (Persea gratissima); plátano (Platanus acerifolia); pereira (Pyrus communis); ameixeira (Prunus domestica); pessegueiro (Prunus persica); goiabeira (Psidium guajava); araticum (Rollinia emarginata) e Ipê (Tabebuia pulcherrima). Desta forma, coloca-se em discussão as possíveis alterações ambientais decorridas da descaracterização da cobertura vegetal.

Para um melhor entendimento das modificações ambientais ocorridas nas regiões de estudo, principalmente no que diz respeito a vegetação, é necessário reportar-se ao final do século XIX, tomando como base a 
colonização de Passo Fundo,RS. A maioria dos dados apresentados foram obtidos através de bibliografia disponível na Universidade de Passo Fundo, que mantém um acervo sobre a região.

Baseado no relato de Oliveira (1990), o povoamento de Passo Fundo teve seu início no começo do século XIX, com a chegada dos europeus que conquistaram o território conhecido como Planalto Médio, onde tropeiros vindos da fronteira sul, dirigiam-se para a província de São Paulo utilizando as terras como pousada. A etnia era composta pelo branco civilizado, o negro, que na época era a principal fonte de trabalho, e o índio que acabou sendo expulso e desapropriado. Os caboclos, descendentes de índios e negros, eram os responsáveis pela coleta da erva-mate, extração da madeira e arrebanhamento do gado. Por volta de 1870, o comércio de exportação de mulas para Sorocaba, erva-mate para os países do Prata e pedra ágata para a Alemanha compunham a base da economia local. Existiam também poucas áreas agriculturáveis sendo porém a grande totalidade do local, constituída de mata araucária. No final do século XIX e início do século XX, o povoado recebeu imigrantes descendentes na sua maioria de italianos, alemães, poloneses e judeus, vindos de outras partes do território rio-grandense. Esse reforço populacional incrementou a indústria manufatureira e o comércio. Em 1893 destacavam-se como agricultura regional, as lavouras de trigo -plantadas inicialmente em meados de 1858- que não prosperavam devido a falta de escoamento do produto e falta de tecnologia no melhoramento da produção. A inauguração da indústria madeireira ocorreu em 1902, intensificando a exploração dos pinhais. Logo essa indústria se tornaria a maior fonte de riqueza local.

Um marco no desenvolvimento de Passo Fundo ocorreu por volta do fim da década de 1950, quando se intensificou a modernização tecnológica na agricultura através de um movimento chamado de penetração capitalista no campo. Ocorreu uma acentuada mecanização em vários setores. O cultivo do trigo tornou-se, inclusive, objeto de incentivo governamental. Neste mesmo 
período, iniciou-se a cultura da soja, também mecanizada, colocando Passo Fundo em um papel de destaque regional no campo socioeconômico-cultural.

A modificação da cobertura vegetal em Passo Fundo, pode ser verificada através do relato de Oliveira (1990), onde na Exposição Nacional de 1902 foi apresentada uma coleção de 102 espécies de madeiras nativas. Já naquela época fazia-se menção especial ao crescente desmatamento provocado pela indústria madeireira.

A partir do incremento das monoculturas, intensificou-se também a utilização dos agrotóxicos. Segundo Ross(1998) "o avanço técnico e científico e o crescente processo de industrialização vêm progressivamente interferindo, agredindo e alterando a natureza, em benefício dos interesses imediatos dos homens".

As regiões de ocorrência de lonomias têm exatamente o perfil citado por Ross(1998). As monoculturas de soja, trigo, algodão e milho por exemplo, são cultivadas em planícies e planaltos como se verifica em Passo Fundo (Fig. 24) Esses cultivos em grandes extensões de terra, facilitam o aparecimento de pragas, que se alimentam dessas plantas. A forma mais rápida e eficiente de combate as pragas é o uso dos inseticidas que são aplicados em grande quantidade. Esses produtos são levados principalmente pelas chuvas e pelo vento, contaminando a flora e a fauna.

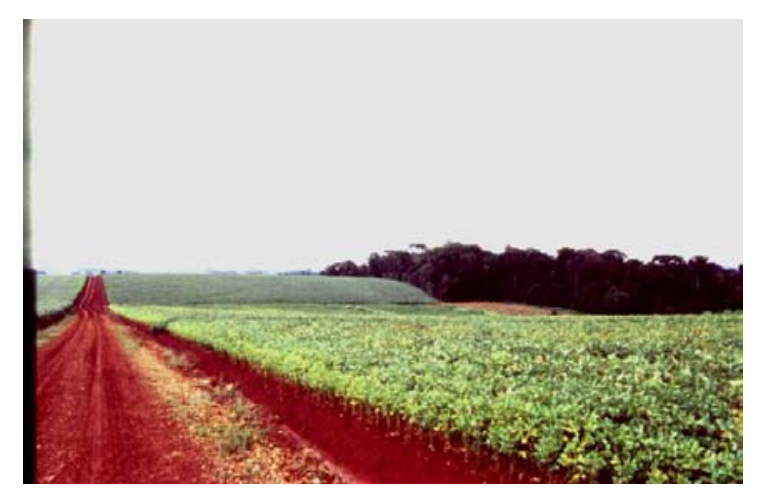

Figura 24 - Área de monocultura em Passo Fundo-RS 
Possivelmente, os agrotóxicos utilizados no Norte do Rio Grande do Sul e extremo Oeste de Santa Catarina, (Anexo F) no decorrer dos anos, tenham afetado as populações de lonomias, interferindo no equilíbrio natural exterminando possíveis inimigos naturais. De outra forma o desmatamento verificado nestas regiões fez com que as lagartas que se alimentavam de folhas de árvores como cedro e aroeira, hoje de pouca ocorrência, passassem a se alimentar de plantas cultivadas nos pomares, onde a presença do homem se faz constante, aumentando assim as possibilidades de contato com as taturanas.

Outro aspecto interessante, verificado nos locais de coleta, é a íntima proximidade da área de cultura com um restante de mata preservada e a residência do proprietário, sempre com um pomar instalado. Nesta mesma propriedade verifica-se a presença de lâmpadas incandescentes, internas e externas, que possibilitam a atração de insetos de várias ordens, incluindo lepidópteros. Discute-se desta forma, a possível atração de lonomias, dos restos de mata preservada para os pomares onde, encontrando alimento farto se adaptaram muito bem .

No extremo Oeste de Santa Catarina, os aspectos bióticos e abióticos são semelhantes aqueles vistos no Rio Grande do Sul. Em São Miguel do Oeste, cidade fundada em 1940, portanto relativamente nova em relação a Passo Fundo, teve o início de sua colonização baseada na exploração da madeira, caracterizada por matas de araucária (Figura 25).
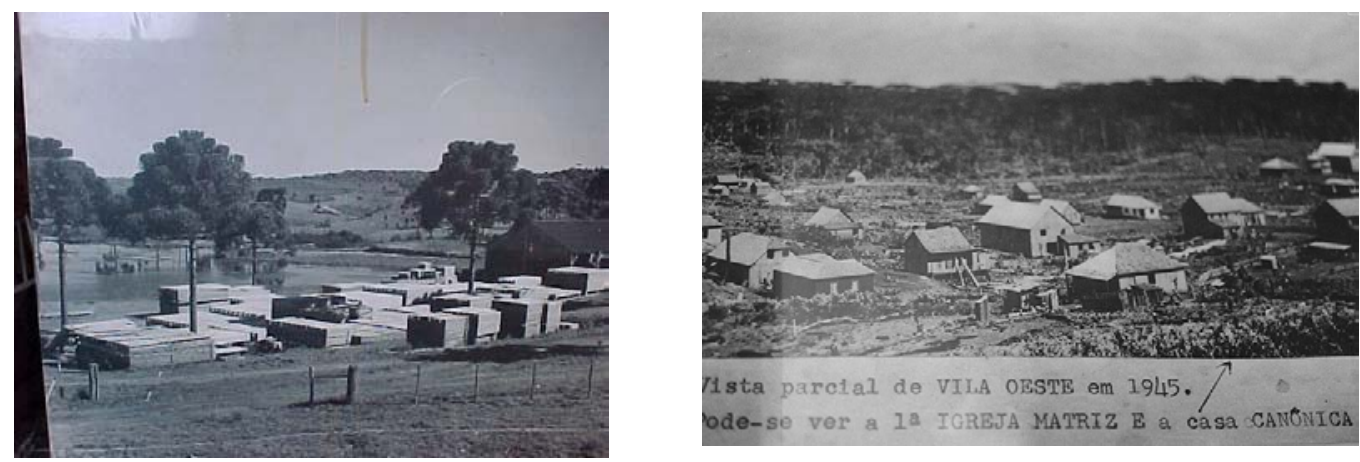

Figura 25 - São Miguel do Oeste-SC. Extração da madeira (E). Aspecto da cidade em 1945, com a exuberante mata ao fundo (D) 
Decorridos apenas sessenta e dois anos da fundação, pouco resta atualmente em S.M.do Oeste da exuberante floresta de pinheiros.

Em São Paulo, tomando-se por base os municípios de Itapecerica da Serra, Cotia e Itapevi (Anexo E), ocais onde ocorreram acidentes hemorrágicos por lonomias, nota-se a diferença de hábitat em relação ao Sul do Brasil. As localidades visitadas são compostas, na grande maioria, de residências de lazer ou moradias definitivas de alto padrão, com a constante presença de uma área preservada. Essas pequenas matas, abrigam lonomias e são delas que se originam os contatos. Geralmente as pessoas transitando por entre as árvores, tocam as lonomias acidentalmente.

Exemplo típico é o Condomínio Transurb, no município de Cotia, distante $35 \mathrm{~km}$ do centro de São Paulo, onde não se observa desmatamento para culturas e sim a invasão legal de matas preservadas onde, os proprietários constroem suas residências no habitat das lagartas (Fig.26).

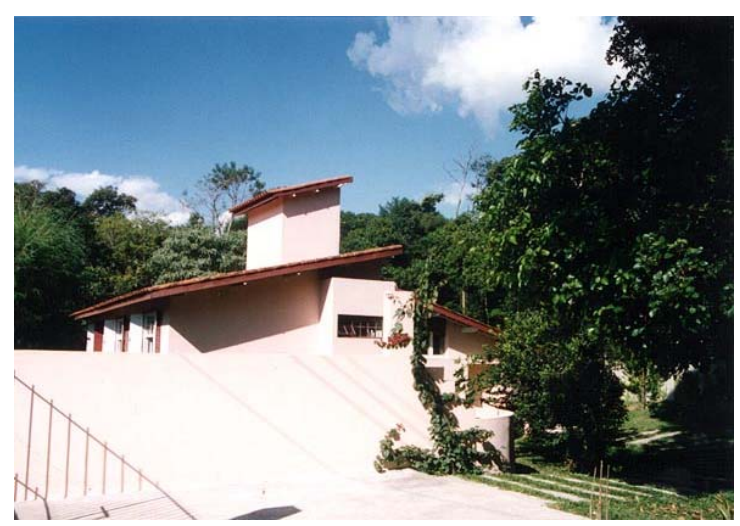

Figura 26 - Condomínio Transurb . Cotia-SP

Comparando-se a forma de acidentes hemorrágicos ocorridos no Sul do Brasil com aqueles ocorridos em São Paulo, constatou-se que neste estado as pessoas têm contatos com as lonomias, quando invadem a mata ainda preservada, caracterizando um acidente propriamente dito. O número de lagartas envolvidas geralmente é pequeno como também o número de 
acidentes. Em contraposição, nos municípios do Sul, os acidentes são geralmente próximos as moradias e no interior dos pomares.

Para se ter uma idéia aproximada da abundância de L.obliqua na região Sul, foram recebidas no Instituto Butantan no ano de 1998, 40.000 lagartas, para a produção do soro antilonômico.

Concluindo, a identificação dos inimigos naturais de L.obliqua do Sul e Sudeste do Brasil, bem como as observações sobre o seu hábitat, deverão ser intensificadas para melhor compreensão do fenômeno. Sendo o problema relativamente recente, muitos pontos são confusos devido a falta de dados e de bibliografia. Novos estudos deverão ser realizados, incluindo o estado do Paraná, onde o número de acidentes vem aumentando. 


\section{CONCLUSÕES}

- São identificações inéditas Moreiria wiedemanni sp.nov (Diptera, Tachinidae) e Lespesia affinis (Diptera, Tachinidae) como inimigos naturais de L.obliqua.

- São inéditos o isolamento e identificação do poliedrovírus LoobMNPV Lonomia obliqua Multiplo Nucleopolyhedrovirus, agente exterminador de colônias de L.obliqua.

- É isolado e identificado pela primeira vez Hexamermis sp (Nematoda, Nemertidae), do tubo digestivo de L.obliqua.

- É observada pela primeira vez a predação sobre lagartas de L. obliqua de Alcaeorrynchus grandis (Hemiptera, Asopinae).

- Belvosia sp.(Diptera,Tachinidae) e Enicospilus sp (Hymenoptera, Ichineumonidae), são citados como inimigos naturais de L.obliqua presentes em lagartas coletadas no Extremo Oeste de Santa Catarina e Sudoeste de São Paulo.

- Os desmatamentos ocorridos nos Estados do Rio Grande do Sul e Santa Catarina bem como o cultivo de monoculturas, provavelmente forçaram a adaptação de L.obliqua as plantas cultivadas próximas as residências.

- A utilização de agrotóxicos nas grandes culturas pode ter exterminado inimigos naturais ainda desconhecidos, desequilibrando o controle natural de L. obliqua.

- Estudos mais aprofundados sobre as duas últimas conclusões deverão ser realizados, visando um melhor entendimento do fenômeno. 
- Todos os inimigos naturais de L.obliqua citados neste trabalho, deverão ser pesquisados quanto a viabilidade de utilização em programas de controle biológico. 
ANEXOS 
ANEXO A . Localidades de estudo

\begin{tabular}{|l|c|c|c|c|c|c|c|}
\hline UF & Município & $\begin{array}{c}\text { Latitude } \\
\mathbf{S}\end{array}$ & $\begin{array}{c}\text { Longitude } \\
\mathbf{W}\end{array}$ & $\begin{array}{c}\text { Altitude } \\
(\mathbf{m})\end{array}$ & $\begin{array}{c}\text { Área } \\
\left(\mathbf{K m}^{2}\right)\end{array}$ & Pop.Urbana & Pop.Rural \\
\hline RS & Carazinho & $28,28^{\circ}$ & $52,78^{\circ}$ & 603 & 909 & 56.276 & 3.618 \\
\hline RS & Chapada & $28,05^{\circ}$ & $53,06^{\circ}$ & 436 & 695 & 4.736 & 5.010 \\
\hline RS & Erval Sêco & $27,54^{\circ}$ & $53,50^{\circ}$ & 425 & 345 & 3.246 & 5.931 \\
\hline RS & F.Westphalen & $27,35^{\circ}$ & $53,39^{\circ}$ & 522 & 264 & 20.433 & 6326 \\
\hline RS & Passo Fundo & $28,26^{\circ}$ & $52,40^{\circ}$ & 687 & 758 & 163.764 & 4.694 \\
\hline SC & Anchieta & $26,53^{\circ}$ & $53,33^{\circ}$ & 710 & 230 & 42243 & 4690 \\
\hline SC & Chapecó & $27,09^{\circ}$ & $52,61^{\circ}$ & 615 & 624 & 134.592 & 12.375 \\
\hline SC & Concórdia & $27,23^{\circ}$ & $52,02^{\circ}$ & 570 & 806 & 45.254 & 17.804 \\
\hline SC & Descanso & $26,82^{\circ}$ & $53,50^{\circ}$ & 553 & 286 & 3.885 & 5.244 \\
\hline SC & Romelãndia & $26,67^{\circ}$ & $53,31^{\circ}$ & 425 & 237 & 2.120 & 4371 \\
& & & & & & & \\
\hline SP & Amparo & $22,70^{\circ}$ & $46,76^{\circ}$ & 675 & 446 & 43.357 & 17.047 \\
\hline SP & Cotia & $26,60^{\circ}$ & $46,91^{\circ}$ & 853 & 324 & 148.987 & 0 \\
\hline SP & Itap. da Serra & $23,71^{\circ}$ & $46,84^{\circ}$ & 906 & 151 & 128.527 & 1.358 \\
\hline SP & Ibiuna & $23,68^{\circ}$ & $47,22^{\circ}$ & 860 & 1060 & 21.356 & 43.028 \\
\hline SP & Itapevi & $23,54^{\circ}$ & $46,93^{\circ}$ & 770 & 91 & 162.433 & 0 \\
\hline SP & Mairinque & $23,54^{\circ}$ & $47,18^{\circ}$ & 850 & 210 & 34.340 & 5.635 \\
\hline SP & Mairiporã & $23,31^{\circ}$ & $46,58^{\circ}$ & 750 & 321 & 48.077 & 12.034 \\
\hline SP & São Paulo & $23,54^{\circ}$ & $46,63^{\circ}$ & 760 & 1525 & 9.813 .187 & 621.065 \\
\hline & & & & & & & \\
\hline
\end{tabular}


ANEXO B

\section{PROTOCOLO Lonomia}

\section{IDENTIFICAÇÃO DO PACIENTE}

\begin{tabular}{|lll|}
\hline PAC. $\mathrm{n}^{\circ}$ & PRT: & \\
IDADE & SEXO ( ) masc ( ) fem & PROFISSÃO \\
ENDEREÇO & & \\
MUNICÍPIO & & ESTADO _ TEL \\
\hline
\end{tabular}

\section{DADOS E CIRCUNSTÂNCIAS DO ACIDENTE}

DATA DO ACIDENTE

HORA

DATA DA ADMISSÃO

HORA

DATA DA ALTA

HORA

MUNICÍPIO ONDE OCORREU O ACIDENTE

ZONA $\square$ urbana $\square$ rural

ATIVIDADE $\square$ trabalho $\square$ lazer $\square$ outra

CONDIÇÕES EM QUE OCORREU O ACIDENTE

NÚMERO DE LAGARTAS QUE PROVOCOU(RAM) O ACIDENTE

LOCAL DE CONTATO
$\square$ mão
antebraço
$\square$ braço
ombro
$\square$ pé
$\square$ perna
$\square$ coxa
nádega
$\square$ tronco
abdome
$\square$ cabeça
pescoço

\section{CARACTERIZAÇÃO DA LAGARTA E DA ÁRVORE}

PACIENTE TROUXE A LAGARTA P/ IDENTIFICAÇÃO $\square$ não $\square$ sim $\mathrm{n}^{\mathrm{o}}$ lagartas que causaram o acidente $\square_{1} \square_{1-10} \square$ 11-20 $\square_{21-30} \square>30$

NOME DA ÁRVORE E/OU ARBUSTO ONDE A LAGARTA FOI CAPTURADA

Fonte: Hospital Vital Brazil - Instituto Butantan 
ANEXO C. Estado do Rio Grande do Sul

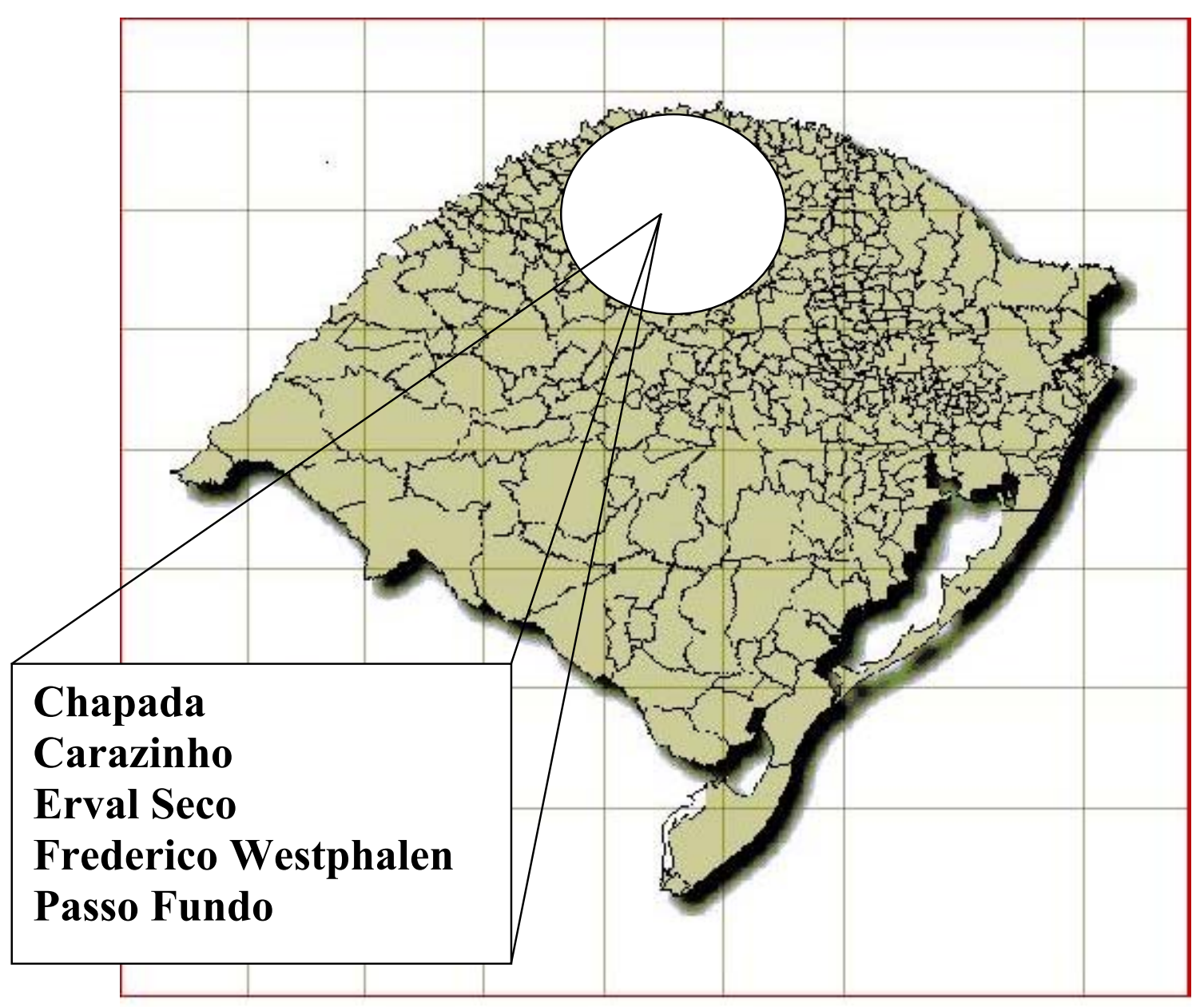

Fonte: IBGE 
ANEXO D. Estado de Santa Catarina

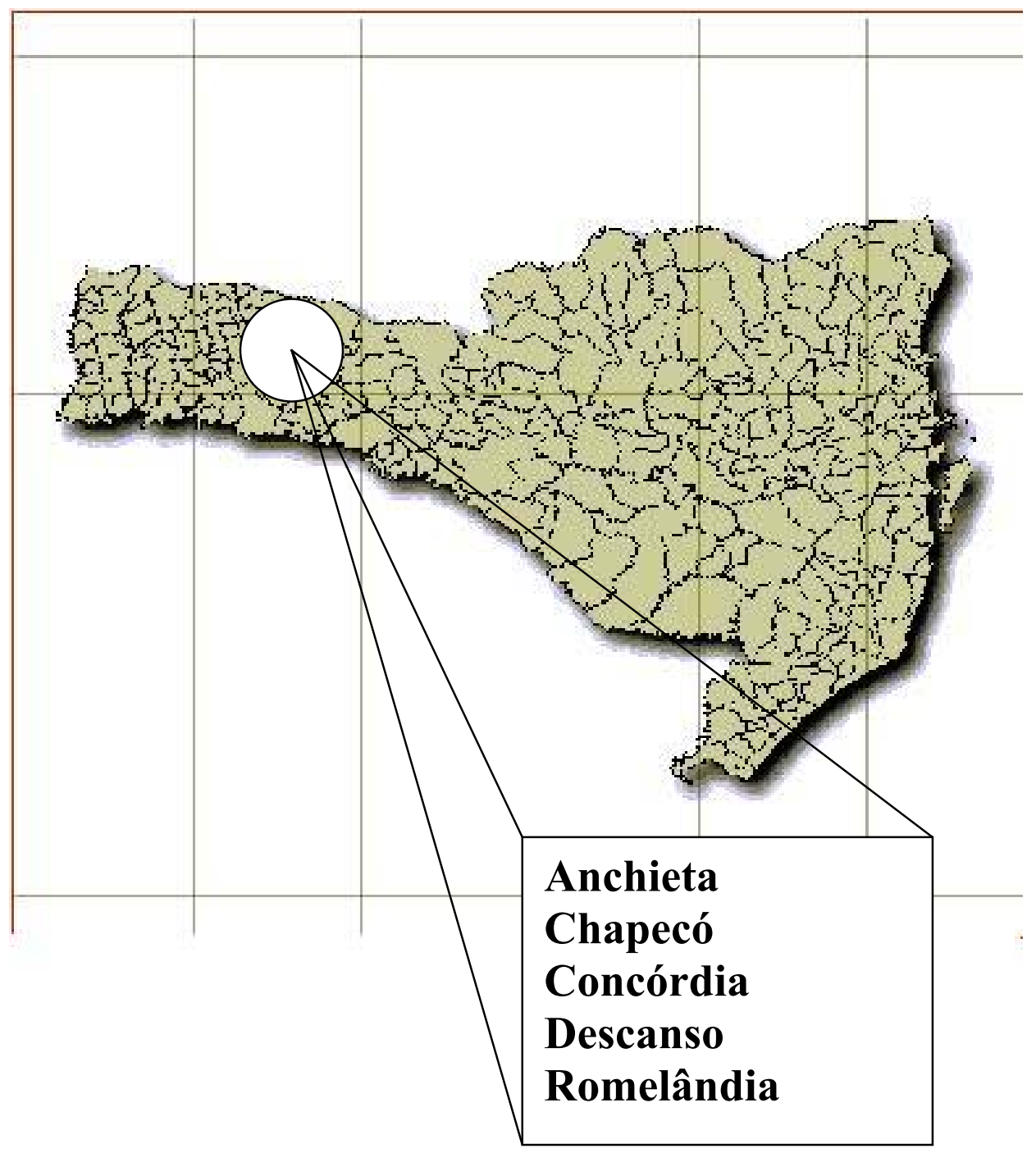

Fonte: IBGE 
ANEXO E. Estado de São Paulo

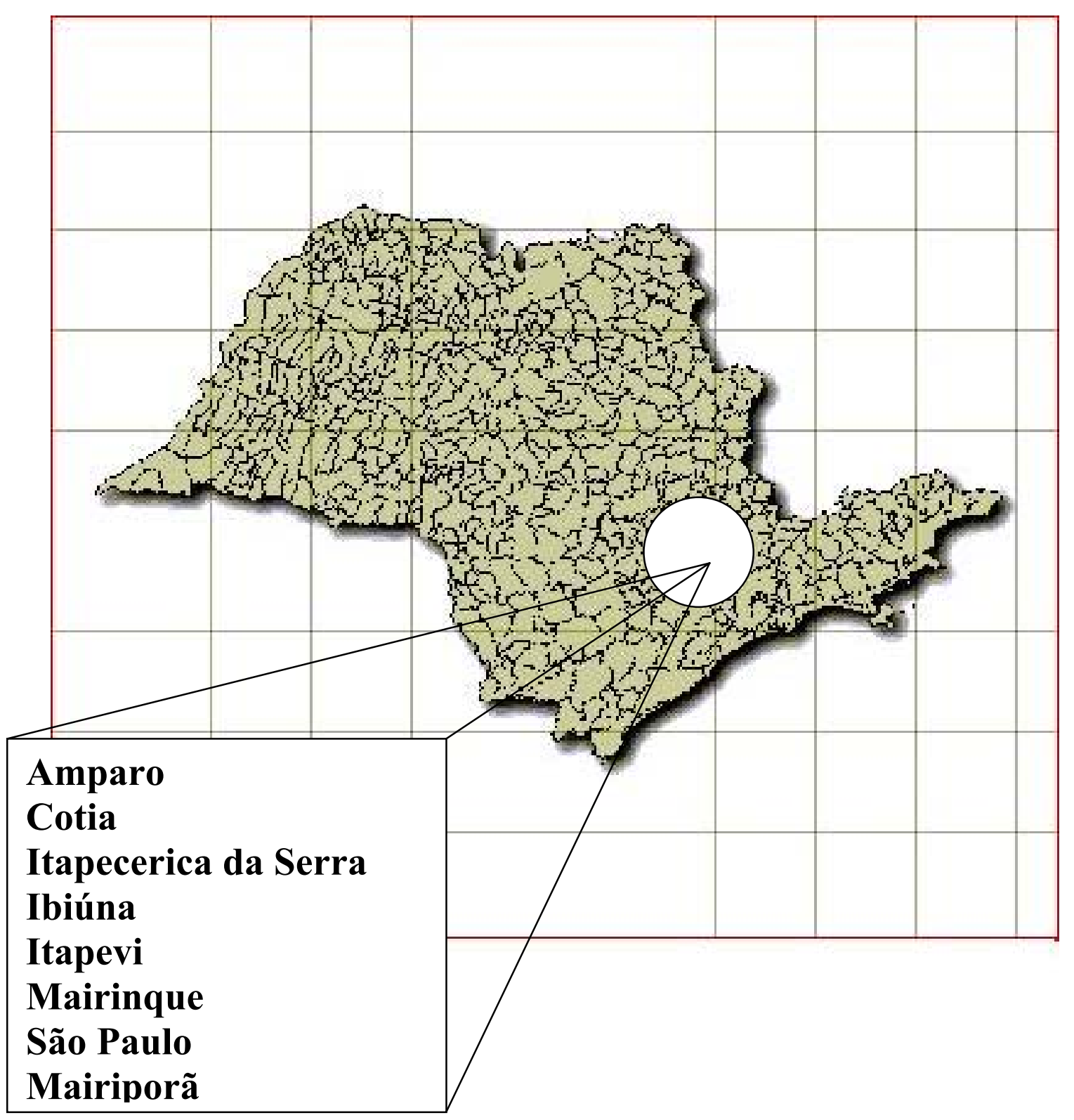

Fonte: IBGE 


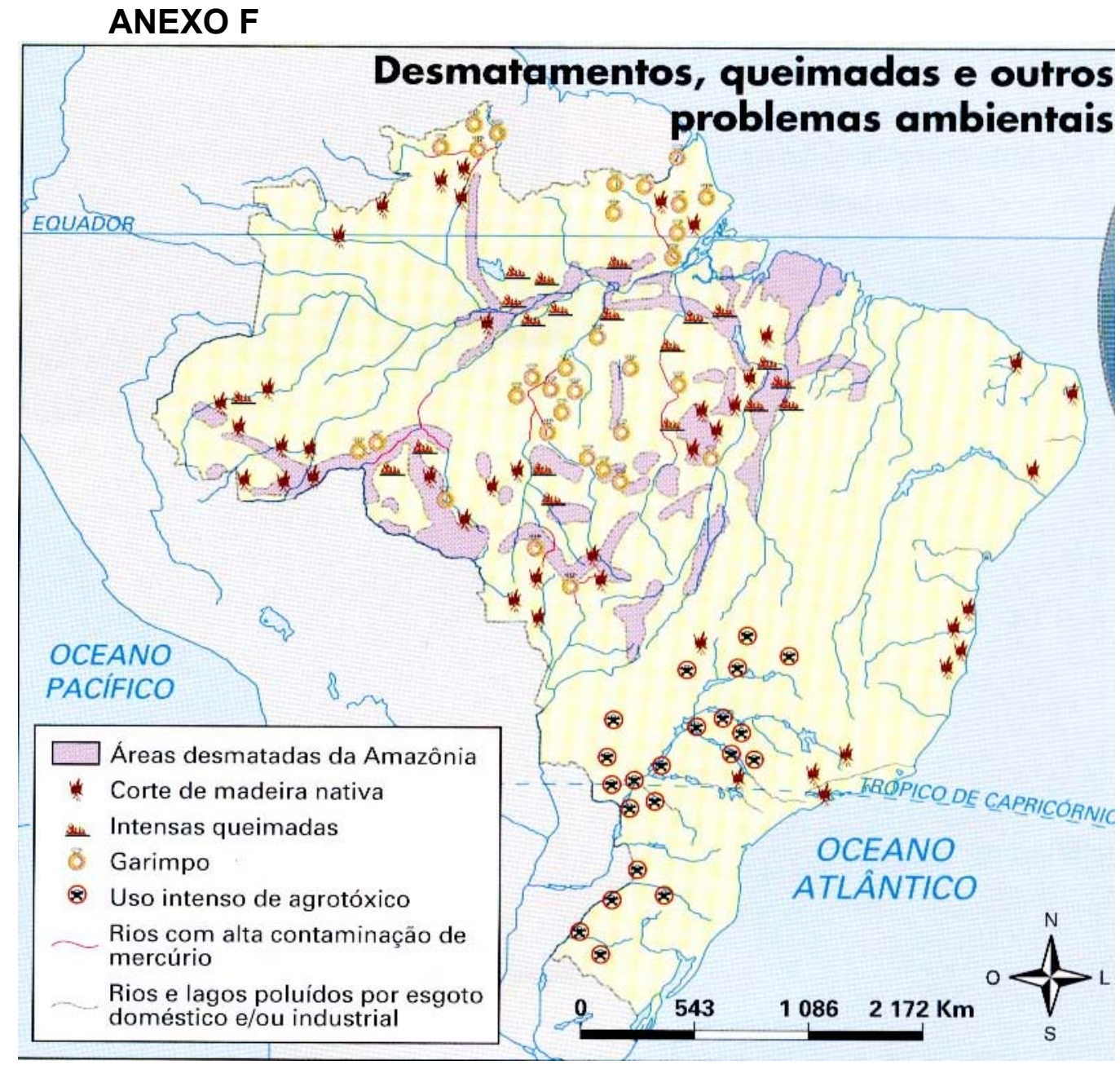

Fonte: Atlas Geográfico FTD,1999 
ANEXO G

SãO MIGUEL DO OESTE-SC código: 421720 Lavoura permanente IBGE

\author{
Descrição \\ Laranja - área destinada à colheita \\ Laranja - área plantada \\ Laranja - quantidade produzida \\ Laranja - rendimento médio \\ Laranja - valor
}

$\begin{array}{cl}\text { Valor } & \text { Unidade } \\ 1,89 & \text { hectare } \\ 1,89 & \text { hectare } \\ 170,1 & \text { fruto } \\ 900 & \text { quilograma/hectare } \\ 1,28 & \text { mil reais }\end{array}$

SãO MIGUEL DO OESTE - SC código: 421720 - Lavoura temporária

\begin{tabular}{cl} 
Valor & Unidade \\
0,07 & hectare \\
0,07 & hectare \\
0,08 & tonelada \\
11,42 & quilograma/hectare \\
0,02 & mil reais \\
0,6 & hectare \\
0,6 & hectare \\
0,91 & tonelada \\
15,16 & quilograma/hectare \\
0,15 & mil reais \\
6,4 & hectare \\
6,4 & hectare \\
2,9 & tonelada \\
4,53 & quilograma/hectare \\
1,51 & mil reais \\
3,06 & hectare \\
3,06 & hectare \\
5,36 & tonelada \\
17,51 & quilograma/hectare \\
9,7 & mil reais \\
1 & hectare \\
1 & hectare \\
20 & tonelada \\
200 & quilograma/hectare \\
3,51 & mil reais \\
55 & hectate \\
55 & hectare \\
156 & tonelada \\
28,36 & quilograma/hectare \\
26,27 & mil reais \\
& \\
\hline
\end{tabular}




\section{ANEXO G (Continuação)}

Soja (grão) - área destinada à colheita

Soja (grão) - área plantada

Soja (grão) - quantidade produzida

Soja (grão) - rendimento médio

Soja (grão) - valor

Trigo (grão) - área destinada à colheita

Trigo (grão) - área plantada

Trigo (grão) - quantidade produzida

Trigo (grão) - rendimento médio

Trigo (grão) - valor
0,8 hectare
0,8 hectare
1,44 tonelada
18 quilograma/hectare
0,38 mil reais
0,15 hectare
0,1 hectare
0,06 tonelada
6 quilograma/hectare
0,01 mil reais 


\section{ANEXO H}

PASSO FUNDO-RS código: 431410 - Lavoura permanente IBGE

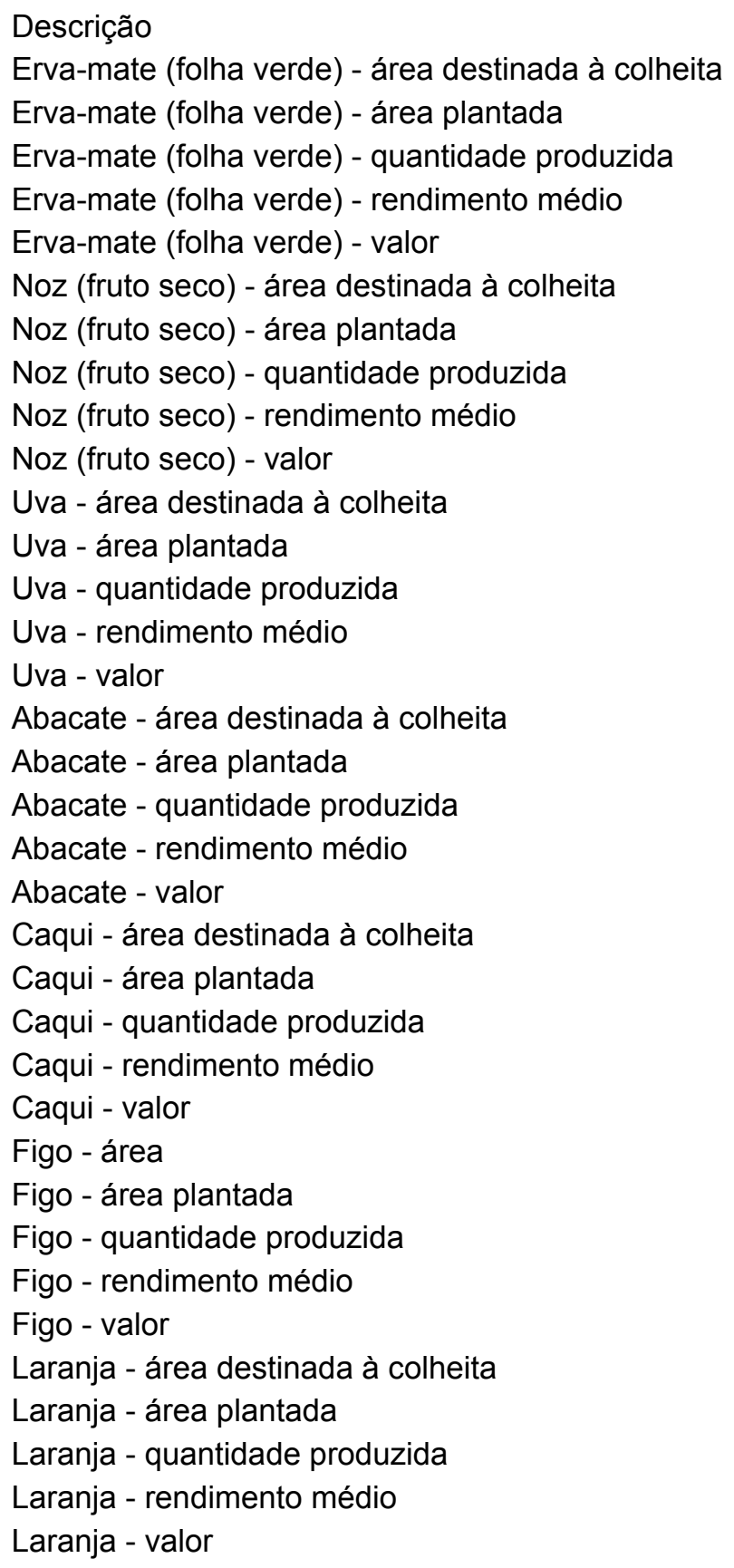

$\begin{array}{cl}\text { Valor } & \text { Unidade } \\ 0,82 & \text { hectare } \\ 0,8 & \text { hectare } \\ 9,6 & \text { tonelada } \\ 120 & \text { quilograma/hectare } \\ 1,76 & \text { mil reais } \\ 0,15 & \text { hectare } \\ 0,15 & \text { hectare } \\ 0,15 & \text { tonelada } \\ 10 & \text { quilograma/hectare } \\ 0,38 & \text { mil reais } \\ 0,12 & \text { hectare } \\ 0,12 & \text { hectare } \\ 1,08 & \text { cacho } \\ 90 & \text { quilograma/hectare } \\ 0,49 & \text { mil reais } \\ 0,02 & \text { hectare } \\ 0,02 & \text { hectare } \\ 0,34 & \text { fruto } \\ 170 & \text { quilograma/hectare } \\ 0,08 & \text { mil reais } \\ 0,1 & \text { hectare } \\ 0,1 & \text { hectare } \\ 11 & \text { fruto } \\ 1100 & \text { quilograma/hectare } \\ 0,8 & \text { mil reais } \\ 0,02 & \text { hectare } \\ 0,02 & \text { hectare } \\ 2,5 & \text { fruto } \\ 1250 & \text { quilograma/hectare } \\ 0,25 & \text { mil reais } \\ 0,33 & \text { hectare } \\ 0,27 & \text { hectare } \\ 18,9 & \text { fruto } \\ 700 & \text { quilograma/hectare } \\ 1,04 & \text { mil reais } \\ & \end{array}$




\title{
ANEXO H (Continuação)
}

\author{
Limão - área destinada à colheita \\ Limão - área plantada \\ Limão - quantidade produzida \\ Limão - rendimento médio \\ Marmelo - área destinada à colheita \\ Marmelo - área plantada \\ Marmelo - rendimento médio \\ Marmelo - valor \\ Pêra - área destinada à colheita \\ Pêra - área plantada \\ Pêra - rendimento médio \\ Pêra - valor \\ Pêssego - área destinada à colheita \\ Pêssego - área plantada \\ Pêssego - quantidade produzida \\ Pêssego - rendimento médio \\ Pêssego - valor \\ Tangerina - área destinada à colheita \\ Tangerina - área plantada \\ Tangerina - quantidade produzida \\ Tangerina - rendimento médio \\ Tangerina - valor
}

0,02

0,02

0,01

0,01

0,28

280

0,01

0,06

0,06

5,4

900

0,42

0,3

0,3

18

600

1,26

0,17

0,17

19,55

1150

1,15

hectare
hectare
fruto
quilograma/hectare
hectare
hectare
fruto
quilograma/hectare
mil reais
hectare
hectare
fruto
quilograma/hectare
mil reais
hectare
hectare
fruto
quilograma/hectare
mil reais
hectare
hectare
fruto
quilograma/hectare
mil reais




\section{ANEXO I}

PASSO FUNDO-RS código: 431410 Lavoura temporária IBGE

\begin{tabular}{|c|c|c|}
\hline Descrição & Valor & Unidade \\
\hline Alho - área destinada à colheita & 0,02 & hectare \\
\hline Alho - área colhida & 0,02 & hectare \\
\hline Alho - quantidade produzida & 0,04 & tonelada \\
\hline Alho - rendimento médio & 20 & quilograma/hectare \\
\hline Alho - valor & 0,12 & mil reais \\
\hline Amendoim (casca) - área destinada à colheita & 0,07 & hectare \\
\hline Amendoim (casca) - área colhida & 0,07 & hectare \\
\hline Amendoim (casca) - quantidade produzida & 0,07 & tonelada \\
\hline Amendoim (casca) - rendimento médio & 10 & quilograma/hectare \\
\hline Amendoim (casca) - valor & 0,07 & mil reais \\
\hline Arroz (casca) - área destinada à colheita & 1 & hectare \\
\hline Arroz (casca) - área plantada & 1 & hectare \\
\hline Arroz (casca) - quantidade produzida & 1,2 & tonelada \\
\hline Arroz (casca) - rendimento médio & 12 & quilograma/hectare \\
\hline Arroz (casca) - valor & 0,24 & mil reais \\
\hline Aveia (grão) - área destinada à colheita & 18 & hectare \\
\hline Aveia (grão) - área plantada & 18 & hectare \\
\hline Aveia (grão) - quantidade produzida & 39,6 & tonelada \\
\hline Aveia (grão) - rendimento médio & 22 & quilograma/hectare \\
\hline Aveia (grão) - valor & 9,94 & mil reais \\
\hline Batata-doce - área destinada à colheita & 0,25 & hectare \\
\hline Batata-doce - área plantada & 0,25 & hectare \\
\hline Batata-doce - quantidade produzida & 3 & tonelada \\
\hline Batata-doce - rendimento médio & 120 & quilograma/hectare \\
\hline Batata-doce - valor & 1,07 & mil reais \\
\hline Batata-inglesa - área destinada à colheita & 0,2 & hectare \\
\hline Batata-inglesa - área plantada & 0,2 & hectare \\
\hline Batata-inglesa - quantidade produzida & 1,8 & tonelada \\
\hline Batata-inglesa - rendimento médio & 90 & quilograma/hectare \\
\hline Batata-inglesa - valor & 0,58 & mil reais \\
\hline Cana-de-açúcar (não forragem) - área destinada à colheita & 0,25 & hectare \\
\hline Cana-de-açúcar (não forragem) - área plantada & 0,25 & hectare \\
\hline Cana-de-açúcar (não forragem) - quantidade produzida & 5,25 & tonelada \\
\hline Cana-de-açúcar (não forragem) - rendimento médio & 210 & quilograma/hectare \\
\hline Cana-de-açúcar (não forragem) - valor & 0,47 & mil reais \\
\hline Cebola - área destinada à colheita & 0,12 & hectare \\
\hline
\end{tabular}




\section{ANEXO I (Continuação)}

\begin{tabular}{|c|c|c|}
\hline Cebola - quantidade produzida & 0,96 & tonelada \\
\hline Cebola - rendimento médio & 80 & quilograma/hectare \\
\hline Cebola - valor & 0,31 & mil reais \\
\hline Cevada - área destinada à colheita & 18 & hectare \\
\hline Cevada - área plantada & 18 & hectare \\
\hline Cebola - área plantada & 0,12 & hectare \\
\hline Cevada - quantidade produzida & 48,6 & tonelada \\
\hline Cevada - rendimento médio & 27 & qilograma/hectare \\
\hline Cevada - valor & 8,8 & mil reais \\
\hline Ervilha - área destinada à colheita & 0,04 & hectare \\
\hline Ervilha - área plantada & 0,04 & hectare \\
\hline Ervilha - quantidade produzida & 0,06 & tonelada \\
\hline Ervilha - rendimento médio & 15 & quilograma/hectare \\
\hline Ervilha - valor & 0,08 & mil reais \\
\hline Feijão (grão) - área destinada à colheita & 1,2 & hectare \\
\hline Feijão (grão) - área plantada & 1,2 & hectare \\
\hline Feijão (grão) - quantidade produzida & 0,68 & tonelada \\
\hline Feijão (grão) - rendimento médio & 5,66 & quilograma/hectare \\
\hline Feijão (grão) - valor & 0,51 & mil reais \\
\hline Mandioca - área destinada à colheita & 1,8 & hectare \\
\hline Mandioca - área plantada & 1,8 & hectare \\
\hline Mandioca - quantidade produzida & 27 & tonelada \\
\hline Mandioca - rendimento médio & 150 & quilograma/hectare \\
\hline Mandioca - valor & 9,45 & mil reais \\
\hline Milho (grão) - área destinada à colheita & 36 & hectate \\
\hline Milho (grão) - área plantada & 36 & hectare \\
\hline Milho (grão) - quantidade produzida & 118,8 & tonelada \\
\hline Milho (grão) - rendimento médio & 33 & quilograma/hectare \\
\hline Milho (grão) - valor & 21,74 & mil reais \\
\hline Soja (grão) - área destinada à colheita & 350 & hectare \\
\hline Soja (grão) - área plantada & 350 & hectare \\
\hline Soja (grão) - quantidade produzida & 567 & tonelada \\
\hline Soja (grão) - rendimento médio & 16,2 & quilograma/hectare \\
\hline Soja (grão) - valor & 154,79 & mil reais \\
\hline Sorgo granífero - área destinada à colheita & 0,3 & hectare \\
\hline Sorgo granífero - área plantada & 0,3 & hectare \\
\hline Sorgo granífero - quantidade produzida & 0,9 & tonelada \\
\hline Sorgo granífero - rendimento médio & 30 & quilograma/hectare \\
\hline Sorgo granífero - valor & 0,1 & mil reais \\
\hline Tomate - área destinada à colheita & 0,1 & hectare \\
\hline
\end{tabular}




\section{ANEXO I (Continuação)}

Tomate - quantidade produzida

Tomate - rendimento médio

Tomate - valor

Trigo (grão) - área destinada à colheita

Trigo (grão) - área plantada

Trigo (grão) - quantidade produzida

Trigo (grão) - rendimento médio

Trigo (grão) - valor

Melancia - área destinada à colheita

Melancia - área plantada

Melancia - quantidade produzida

Melancia - rendimento médio

Melancia - valor

Melão - área destinada à colheita

Melão - área plantada

Melão - quantidade produzida

Melão - rendimento médio

Melão - valor

$\begin{array}{cl}4 & \text { tonelada } \\ 400 & \text { quilograma/hectare } \\ 2,01 & \text { mil reais } \\ 30 & \text { hectare } \\ 30 & \text { hectare } \\ 72 & \text { tonelada } \\ 24 & \text { quilograma/hectare } \\ 13,54 & \text { mil reais } \\ 0,05 & \text { hectare } \\ 0,05 & \text { hectare }\end{array}$

$0,1 \quad$ fruto

20

0,12

0,02

0,02

0,03

15

0,03 quilograma/hectare

mil reais

hectare

hectare

fruto

quilograma/hectare

mil reais 


\section{REFERÊNCIAS BIBLIOGRÁFICAS}

ALVARENGA, Z. A taturana. In: VII Congresso Brasileiro de Medicina e Cirurgia, Belo Horizonte, 1912. Anais. V.2, p. 132-135.

ALVES, S.B. Controle microbiano de insetos. São Paulo: Manole ed., 1986. $407 p$.

AROCHA-PIÑANGO, C.L.; LAYRISSE, M. Fibrinolysis produced by contact with a caterpillar. Lancet, v.1, n.7599, p. 810-812, 1969.

AROCHA-PIÑANGO, C. L.; PERALES, J.; ARVAJAL, Z. Studies on the degradation of fibrinogen by proteolytic enzymes from the larvae of Lonomia achelous (Cramer). Thromboses ans Haemostasis, v.45, p.233236, 1981

BARTH, R. Estudos histológicos das células glandulares dos insetos peçonhentos. Memórias do Instiuto Oswaldo Cruz. v.52, p. 124-367, 1954.

BECKER, V. O.; CARCASSON, R.H.; HEPPNER, J.B.; LEMAIRE, C. Atlas of neotropical lepidoptera: Checklist: part 42, Drepanoidea, Bombycoidea, Sphingoidea. Florida: J.B.Heppner, 1996.

BIEZANKO, C.M.; BERTHOLDI, R. E.; BAUCKE, O. Relação dos principais insetos prejudiciais observados nos arredores de Pelotas nas plantas cultivadas e selvagens. Agros,v.2, p.156-213, set., 1949.

BURDMANN, E. A.; ANTUNES, I.; SALDANHA, L. B.; ABDULKADER, R. C. Severe acute renal failure induced by the venom of Lonomia caterpillars. Clinical Nephrology, v. 46, n. 5, p. 337-339, 1996 
CARDOSO, J.L.C. Lepidopterismo. In: SCHVAARTSMAN, S. Plantas venenosas e animais peçonhentos. São Paulo: Sarvier, 1992. cap.17, p.237-238.

COSTA, R.M. Artropatia da Pararamose: epidemiologia, clínica e modelos experimentais. São Paulo, 1991. 92p. Tese (Doutorado) - Escola Paulista de Medicina.

D'ANTONIO, A. M. Biologia, nutrição quantitativa e danos de Lonomia circumstans (Walker, 1855) (Lepidoptera, Attacidae) em cafeeiro. Piracicaba, 1983. 69p. Dissertação (Mestrado) - Escola Superior de Agricultura "Luiz de Queiroz" , Universidade de São Paulo.

D'ABRERA, B. Saturniidae mundi: saturniid moths of the world. London: Automeris Press; Hill House, 1995. pt.1, p.102-106.

DIAS DA SILVA, W.; CAMPOS, A. C. M. R.; GONÇALVES, L.R.C.; SOUSA-ESILVA, M.C.C; HIGASHI, H.G.; YAMAGUSHI, I.K.; KELEN, E.M.A. Development of an antivenom against toxins of Lonomia obliqua caterpillars. Toxicon, v.34, n.9. p 1045-1049, 1996.

DUARTE, A.C.; CAOVILLA, J.; LORINI, I.; LORINI,D.; MANTOVANI, G.; SUMIDA, J.; MANFRE, P.C.; SILVEIRA, R.C.; MOURA, S.P. Insuficiência renal aguda por acidentes com lagartas. Jornal Brasileiro de Nefrologia, v.12, n.4, p.184-187, 1990.

FAN, H. W., CARDOSO, J. L. C.; OLMO, R. D.; ALMEIDA, F. J.; VIANA, R. P., MARTINEZ, A. P.P. Hemorrhagic syndrome and acute renal failure in a pregnant woman after contact with Lonomia caterpillars: a case report. Revista do Instituto de Medicina Tropical de São Paulo, v.40, p.119-120, 1998

FRAIHA, H.; BALLARINI, A. J.; LEÃO, R.N.Q.; COSTA JUNIOR, D.; DIAS, L. B. Síndrome hemorrágica por contato com larvas de mariposa (Lepidoptera, Saturniidae). Inst. Evandro Chagas, 50 anos de contribuição às ciências biológicas e à medicina tropical, v.2, p.811-820, 1986 (número especial) 
GALLO, D.; NAKANO, O.; SILVEIRA NETO, S.; CARVALHO, R. P. L., BATISTA, G. C.; BERTI FILHO, E.; PARRA, J. R. P.; ZUCCHI, R. A.; ALVES, S. B.; VENDRAMIM, J. D. Manual de entomologia agrícola. São Paulo: CERES, 1988. cap.10, p. 321-639: Pragas das plantas e seu controle.

HAMBLETON, E.J.; FORBES, W.T.M. Uma lista de lepidoptera (heterocera) do estado de Minas Geraes. Archivos do Instituto Biológico, v.6, p.213-256, 1935. Suplemento,2.

INSTITUTO BRASILEIRO DE GEOGRAFIA E ESTATÍSTICA. Base de informações municipais. 2.ed. Rio de Janeiro, 2000b. (CD-Rom)

INSTITUTO BRASILEIRO DE GEOGRAFIA E ESTATÍSTICA. Enciclopédia dos municípios brasileiros. Rio Grande do Sul, vol. 18, edição facsimilar. Rio de Janeiro, 2000a (CD-Rom).

INSTITUTO BRASILEIRO DE GEOGRAFIA E ESTATÍSTICA. População. Censo 2000 - Sinopse preliminar Rio Grande do Sul. http://www1.ibge.gov.br/ibge/estatistica/populacao/censo2000/sinopse.php? tipo=21\&uf=43 ( 09 ago. 2001$)$

IHERING, R. V. Contos de um naturalista. Annaes Paulista de Medicina e Cirurgia, p.72-91, 1914.

KELEN, E. M. A.; PICARELLI, Z. P.; DUARTE, A. C. Hemorrhagic syndrome induced by contact with caterpillars of the genus Lonomia (Saturniidae, Hemileucinae). Journal Toxicology v.14, n.3, 283-308, 1995.

LEMAIRE, C. Révision du genre Lonomia Walker (Lep. Attacidae). Annaes de la Societe Entomologique du France. (N.S.), v.8, n.4, p.767-861, 1972.

LIMA, A.C. Catálogo systematico dos insectos que vivem nas plantas do Brasil e ensaio de bibliographia entomologica brasileira. Archivos da Escola Superior de Agricultura e Medicina Veterinária, v.6, n. 1/2, p.107-276, dez 1922. 
LIMA, A.M.C. Terceiro catálogo dos insectos que vivem nas plantas do Brasil. Ministerio da Agricultura. Rio de Janeiro: Departamento Nacional da Produção Vegetal. Escola Nacional de Agronomia. 1936. 460p.

LIMA, A. C. Insetos do Brasil: Hemípteros. Rio de Janeiro: Imprensa Nacional, Escola Nacional de Agronomia, 1940.

LORINI, L.M. A taturana: aspectos biológicos e morfológicos da Lonomia obliqua. Passo Fundo: Editora da Universidade de Passo Fundo, 1999. $67 p$.

MICHENER, C.D. The saturniidae (lepidoptera) of the western hemisphere: morphology, phylogeny and classification. Bulletin of the American Museum of Natural History, v.98, n. 5, p.335-502, Mai, 1952.

MORAES, R.H.P.; TRAVASSOS-FILHO, L. P. Contribuição para o conhecimento das lagartas urticantes. Memórias do Instituto Butantan, v.44/45, p.367-376, 1980/81

MORAES, R. H. P.; VEIGA-BARREIROS, R. M. O.;MARASSÁ, A. M.; ZORZENON. F. J.; ANDRADE, R. M. G.; CASTILLO, A. Obtenção de dois inimigos naturais em criação de Lonomia Walker (Lepidoptera, Saturniidae). In: ENCONTRO NACIONAL DE ACIDENTES POR ANIMAIS PEÇONHENTOS, Porto Alegre, 1992. Programa científico. Porto Alegre: Hospital de Clínicas de Porto Alegre, 1992 . p.40.

MORAES, R.H.P. Lagartas urticantes. Biológico, v.59, n.2, p. 21-25, 1997.

OLIVEIRA, F. Annaes do município de Passo Fundo: aspecto geográfico. Passo Fundo: Gráfica e Ed. Universidade de Passo Fundo, 1990a. v.1, $363 p$.

OLIVEIRA, F. Annaes do município de Passo Fundo. Aspecto histórico. Passo Fundo: Gráfica e Ed. Universidade de Passo Fundo, 1990b, v.2, $426 p$.

O’REILLY, D.R.; MILLER, L.K.; LUCKNOW, V.A. Baculovirus expression vectors: a laboratory manual. New York: WH Freeman. 1992. 
PREDATORYstinkbug.<http://creatures.ifas.ufl.edu/beneficial/a_grandis.htm> (01 mai. 2002)

PARRA, J.R.P. Técnicas de criação de insetos para programas de controle biológico. Piracicaba: ESALQ, 1990

PESSOA, S.B. ; MARTINS, A.V. Parasitologia médica. Rio de Janeiro: Ed. Guanabara Koogan, 1973. 1002p.

REIS, C. V.; KELEN, E.M.A.; FARSKY, S.H.P.; PORTARO, C.A.M.; SAMPAIO, C.A.M.; FERNANDES, B. L.; CAMARGO, A.C.M.; CHUDZINSKI-TAVASSI, A.M. A Ca++ activacted serine protease (Lopap) could be responsible for the haemorrhagic syndrome caused by caterpillar Lonomia obliqua. Lancet, v.353, p. 1942, 1999.

RICHARDS, O.W.; DAVIES, R.G. IMMS' general textbook of entomology. 10ed. London: Chapman \& Hall, 1977. 2 v.

RICHMAN, D.B.; WHITCOMB, W.H. Comparative life cycles of four epecies of predatory stink bugs(Hemiptera:Pentatomidae). Florida Entomology, p. 113-119, 1978.

ROSS, J.L.S. Geografia do Brasil. São Paulo: EDUSP, 1998. 549p.

SCHLOTTFELDT, C.S. Insetos encontrados em plantas cultivadas e comuns Viçosa, Minas Gerais. Revista Ceres, v.6, n.31, p.52-65, 1944.

SILVA, A.G.D'A.; GONÇALVES, C.R.; GALVÃO, D.M.; GONÇALVES, A.J.L.; GOMES, J.; SILVA, M.N.; SIMONI, L. Quarto catálogo dos insetos que vivem nas plantas do Brasil: seus parasitos e predadores. Bibliografia entomológica brasileira, Parte I, tomo2, Ministério da Agricultura, Departamento de defesa e inspeção agropecuária. Serviço de defesa sanitária vegetal. Laboratório central de patologia vegetal: Rio de Janeiro. 1967, 906p.

SILVA, A.G.D'A.; GONÇALVES, C.R.; GALVÃO, D.M.; GONÇALVES, A.J.L.; GOMES, J.; SILVA, M.N.; SIMONI, L. Quarto catálogo dos insetos que vivem nas plantas do Brasil: seus parasitos e predadores. Insetos, hospedeiros e inimigos naturais. Parte II, tomo1, Ministério da Agricultura, 
Departamento de defesa e inspeção agropecuária. Serviço de defesa sanitária vegetal. Laboratório central de patologia vegetal: Rio de Janeiro. 1968, 622p.

STEINHAUS, E. A. Principles of insect pathology. New York: McGraw-Hill Book, 1949. 757p.

TECHNICAL BULLETIN $218 \quad-\quad$ Nematode infections :http://msucares.com/pubs/tb218nematode.htm. (12 abr.2002)

TOMA, R., GUIMARÃES, J.H. Moreiria wiedwmanni sp.nov. e redescrição de M. maura (Díptera, Tachinidae). Iheringia, Série Zoologica. v. 91, p. 4952, 2001.

VEIGA, A. B. G.; BLOCHTEIN, B.; GUIMARÃES, J. A. Structures involved in production, secretion and injection of the venom produced by the caterpillar Lonomia obliqua (Lepidoptera, Saturniidae). Toxicon, v. 39, p.1343-1351, 2001. 